\title{
Anatomical and molecular imaging of skin cancer
}

\author{
Hao Hong' \\ Jiangtao Sun' \\ Weibo Cai ${ }^{1,2}$ \\ 'Departments of Radiology and \\ Medical Physics, School of Medicine \\ and Public Health, University of \\ Wisconsin - Madison, Madison, \\ Wisconsin, USA; ${ }^{2}$ University \\ of Wisconsin Paul P. Carbone \\ Comprehensive Cancer Center, \\ Madison, Wisconsin, USA
}

\begin{abstract}
Skin cancer is the most common form of cancer types. It is generally divided into two categories: melanoma $(\sim 5 \%)$ and nonmelanoma ( $\sim 95 \%)$, which can be further categorized into basal cell carcinoma, squamous cell carcinoma, and some rare skin cancer types. Biopsy is still the gold standard for skin cancer evaluation in the clinic. Various anatomical imaging techniques have been used to evaluate different types of skin cancer lesions, including laser scanning confocal microscopy, optical coherence tomography, high-frequency ultrasound, terahertz pulsed imaging, magnetic resonance imaging, and some other recently developed techniques such as photoacoustic microscopy. However, anatomical imaging alone may not be sufficient in guiding skin cancer diagnosis and therapy. Over the last decade, various molecular imaging techniques (in particular single photon emission computed tomography and positron emission tomography) have been investigated for skin cancer imaging. The pathways or molecular targets that have been studied include glucose metabolism, integrin $\alpha_{v} \beta_{3}$, melanocortin-1 receptor, high molecular weight melanoma-associated antigen, and several other molecular markers. Preclinical molecular imaging is thriving all over the world, while clinical molecular imaging has not lived up to the expectations because of slow bench-to-bedside translation. It is likely that this situation will change in the near future and molecular imaging will truly play an important role in personalized medicine of melanoma patients.
\end{abstract}

Keywords: skin cancer, molecular imaging, melanoma, anatomical imaging, positron emission tomography, antibody

\section{Introduction}

Skin cancer is the most common form of cancer in the United States with more than 1 million new cases diagnosed annually (http://www.skincancer.org). It is estimated that one in five Americans and one in three Caucasians will develop skin cancer in their lifetime (http://www.cancer.gov). Skin cancers are generally divided into two categories: melanoma (the most serious form of skin cancer) and nonmelanoma (Mueller and Reichrath 2008; Rass and Tilgen 2008). Nonmelanoma can be further categorized into two main types: basal cell carcinoma (BCC) and squamous cell carcinoma (SCC) (Figure 1). BCC, the most common form of skin cancer, is rarely fatal but can be highly disfiguring. SCC is the second most common form of skin cancer. Together, BCC and SCC constitutes approximately $95 \%$ of nonmelanoma skin cancers (NMSCs) (Tillman and Carroll 2007). Besides the cancer types mentioned above, there are also certain unusual skin cancer types such as Merkel cell carcinoma and Kaposi' sarcoma (Douglas et al 2007; Tai 2008). Some precancerous lesion, such as actinic keratosis (Rossi et al 2007; Schwartz et al 2008), has also been reported.

If skin cancers are diagnosed and treated early, they are nearly 100 percent curable. However, correct diagnosis can not always be unequivocally reached. Direct visual inspection of the skin, depending on the experience of the clinician, is often suboptimal for skin cancer diagnosis. Currently, conventional histopathology detection (biopsy) is still the gold standard for skin cancer evaluation. However, there are many disadvantages associated with biopsy. It is painful, relatively expensive, time-consuming, and typically 
accompanied with scar formation. In many cases, several biopsies will be needed before a diagnosis can be confirmed. Furthermore, histology does not allow repeated observation of dynamic processes over time, such as monitoring the therapeutic effects of a certain drug.

To overcome such disadvantages, many imaging modalities have been investigated for noninvasive diagnosis of skin cancer. Various anatomical imaging techniques, and more recently molecular imaging techniques, have been used to evaluate different types of skin cancer lesions. In this review article, we will summarize the progress to date on anatomical and molecular imaging techniques of skin cancer. With the ultimate goal beyond more accurate, pain-free diagnosis, some of these methods can also be used for monitoring the therapeutic efficacy of skin cancer intervention.

\section{Anatomical imaging}

Development of noninvasive, high-resolution techniques for anatomically imaging skin cancers or skin related lesions in situ can increase the diagnostic accuracy. The most promising techniques with anatomical accuracy include laser scanning confocal microscopy (CM) (Astner et al 2008; Gerger et al 2008; Nehal et al 2008), optical coherence tomography (OCT) (Gambichler et al 2007a; Gambichler et al 2007b; Salvini et al 2008), high-frequency ultrasound (HFUS) (DillMuller and Maschke 2007; Schmid-Wendtner and Burgdorf 2005), terahertz pulsed imaging (TPI) (Mogensen and Jemec 2007; Wallace et al 2004), and magnetic resonance imaging (MRI) (Campbell and Campbell 2006; Mogensen and Jemec 2007). CM has exceptional spatial resolution yet it suffers from poor tissue penetration. OCT, HFUS, and MRI can acquire full thickness, vertical optical sections, however their resolution is relatively limited and can not reach the cellular level. There are also some recently developed techniques for skin cancer imaging, such as fluorescence remission sensoring (Wollina et al 2007), Raman spectroscopy (Lieber et al 2008; Naito et al 2008), and photoacoustic microscopy (Zhang et al 2006).

\section{Confocal microscopy}

CM, first described about half a century ago (Minsky 1988), is a technique in which a laser is focused on the specific point in the skin to selectively collect light from in-focus planes in the tissue. It offers the highest resolution (comparable to routine histology) among all these techniques. The latest CM systems can offer micrometer $(\mu \mathrm{m})$-level axial resolution and sub- $\mu \mathrm{m}$ lateral resolution (Astner et al 2008; Gerger et al 2008; Nehal et al 2008). Therefore, it is possible to study the skin on the cellular/subcellular level in vivo with $\mathrm{CM}$ and application of this imaging modality to skin visualization during the last decade has been an exciting area in dermatology (Gonzalez and Gilaberte-Calzada 2008; Nehal et al 2008).

As a noninvasive imaging method, $\mathrm{CM}$ is frequently used for the diagnosis of skin cancer (Gerger et al 2008; Mogensen and Jemec 2007; Ulrich et al 2007). Basal and squamous cell carcinomas (Agero et al 2006; Horn et al 2007; Patel et al 2007; Tillman and Carroll 2007), melanocytic nevi and melanomas (Gerger et al 2008; Happe et al 1997; Langley et al 2007; Ono et al 2006; Pellacani et al 2005b), as well as actinic keratoses (Aghassi et al 2000; Ulrich et al 2008), have all been imaged successfully with CM. In melanocytic lesions, the endogenous contrast provided by melanin and melanosomes can allow for the differentiation of benign versus malignant tissues. In nonmelanoma lesions, the morphologic characteristics visualized by CM has been reported to be in good correlation with histology (Astner et al 2008). For example, common features of actinic keratose and $\mathrm{BCC}$ in $\mathrm{CM}$ images include nuclear pleomorphism in the granular and spinous layer, and increased vascularity in the superficial dermal compartment (Ulrich et al 2008).

Three-dimensional (3D) reconstruction of skin tumors using CM was reported in 2006 (Ono et al 2006). Such reconstruction, using more sophisticated computing algorithm and potentially enabling more accurate imaging, was able to successfully differentiate benign and malignant skin tissues. More research needs to be undertaken before such 3D CM can be used for clinical applications. Taken together, CM imaging is a promising noninvasive tool in the differential diagnosis of benign and malignant pigmented skin lesions. Greater than $90 \%$ positive predictive value has been reported for the differentiation of benign and malignant skin lesions (melanoma and BCC) (Gerger et al 2006).

The advantages of in vivo $\mathrm{CM}$ over conventional histology are several-fold. First, CM is painless and noninvasive which does not cause tissue damage or require staining. Second, the data collection process is quite fast and can allow for repeated observation of dynamic process in real time. Therefore, $\mathrm{CM}$ has been used for longitudinal evaluation of physiological events (Patel et al 2007; Pellacani et al 2005a; Segura et al 2007), disease progression over time (Agero et al 2006; Scope et al 2007), and response to therapy (Astner et al 2008; Paolino et al 2008). On the other hand, there are also many disadvantages associated with CM. First, the depth of imaging (about $250 \mu \mathrm{m}$ ) is limited to the superficial dermis due to tissue-induced scattering and aberrations. Second, the grayscale contrast in the CM image 


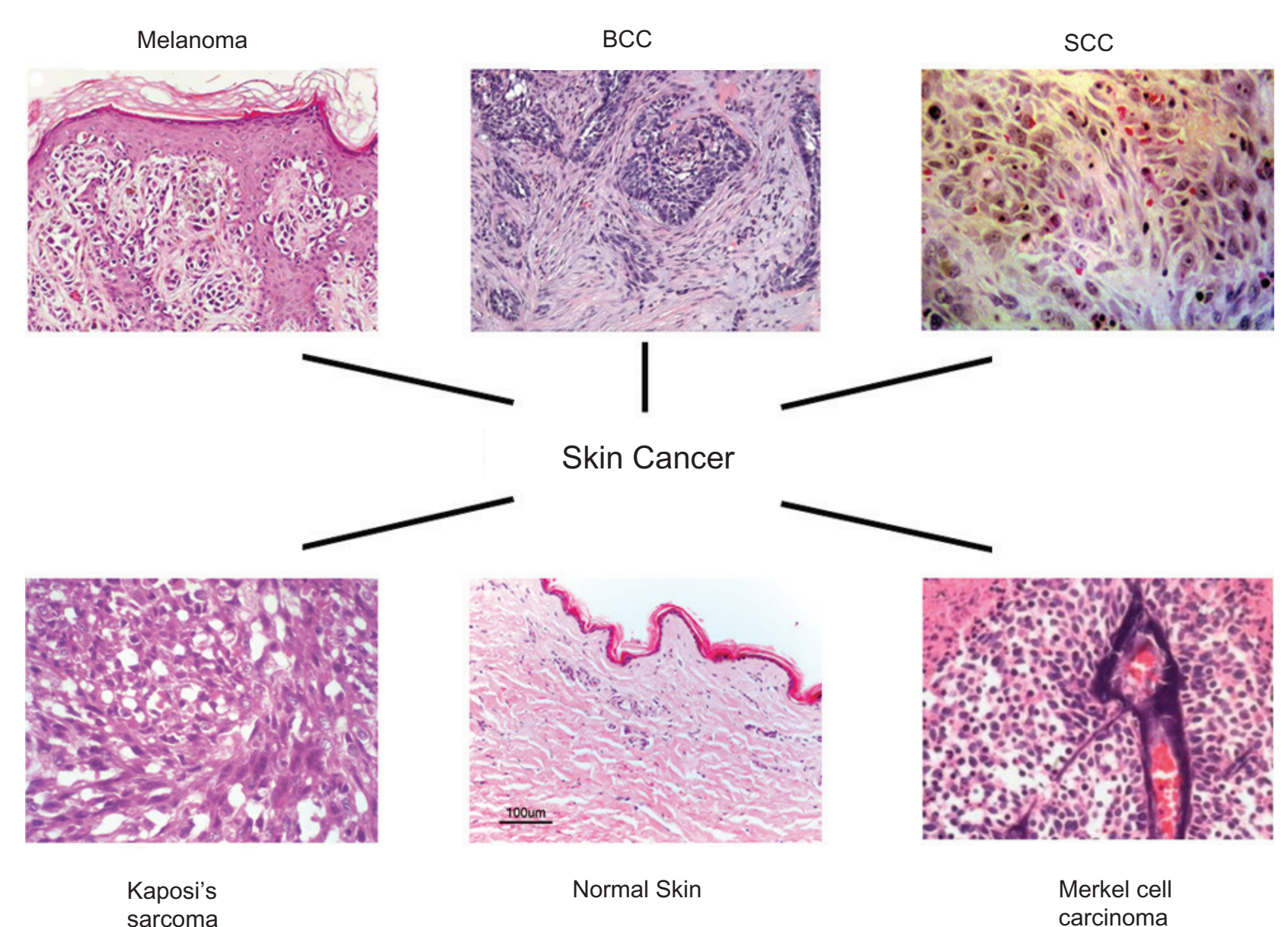

Figure I The characteristic histology of melanoma, BCC, SCC, and some rare skin cancer subtypes (Kaposi's sarcoma and Merkel cell carcinoma). Adapted from (Carless and Griffiths 2008; Crowson 2006).

lacks specificity for organelles and ultrastructure. Lastly, CM is encumbered by the small field of view and the mirror-based design. The instrumentation is relatively expensive and large, therefore difficult to use on certain anatomical sites. Taking all the factors into consideration, $\mathrm{CM}$ can serve as a powerful imaging modality for improving the diagnostic accuracy of skin cancer, yet it should not be used independently without other techniques.

\section{Optical coherence tomography}

OCT, based on light scattering, can be used to image microscopic structures in vivo at a resolution of a few $\mu \mathrm{m}$ and to a depth of 1-3 mm (Gambichler et al 2007a; Gambichler et al 2007b; Salvini et al 2008). It is analogous to B-mode ultrasound pulse-echo imaging except that the optical rather than the acoustic reflectivity is measured. Linear characteristics such as scattering, absorption, birefringence, and refractive index are measured to produce the OCT images, which can also be enhanced by Doppler function. Capable of acquiring cross-sectional, high-resolution images of structures below the tissue surface (Fujimoto et al 2000; Gambichler et al 2005; Pierce et al 2004), OCT can enable the differentiation of healthy tissue from cancerous tissue based on simple visual analysis, which can be quite difficult with other techniques since typically there is no boundary between the cancerous and normal tissue (Gambichler et al 2007a). Recently, OCT was used to evaluate skin vascular lesions, which provided a new perspective for OCT in noninvasive diagnostics (Salvini et al 2008). OCT is currently being evaluated clinically in several countries, and it as already been approved for medical diagnosis in several others (Fujimoto 2003; Fujimoto et al 2000).

Although OCT has been investigated in many areas of dermatology, it was not systematically studied in skin cancer (eg BCC and melanoma) until 2006 (Gambichler et al 2007a; Gambichler et al 2007b; Olmedo et al 2006). In BCC, OCT is capable of visualizing altered skin architecture with good correlation to histopathology. Compared to the normal tissue, a loss of normal skin architecture and disarrangement of the epidermis and upper dermis was observed in OCT 
images of BCCs. Features that were frequently identified by OCT include large plug-like signal-intense structures, honeycomb-like signal-free structures, and the prominent signal-free cavities in the upper dermis (Gambichler et al 2007a), all of which correlated well with the histologic findings. Such consistency with histology was also established in benign or malignant melanocytic skin lesions (Gambichler et al 2007b). Melanoma often showed marked architectural disarray, rarely displaying a clear dermoepidermal border, when compared with benign nevi. The icicle-shaped structures were the most striking OCT feature of melanoma, which were not present in benign nevi. Since OCT is a relatively new technique for skin cancer diagnosis, there is not enough data yet to support the clinical use of OCT only for the differentiation of skin cancer subtypes. The diagnostic performance of OCT in melanoma can not be fully determined without histological confirmation.

Another application of OCT is to estimate the superficial thickness of skin cancers (eg, BCCs) to facilitate surgery preparation (Olmedo et al 2007). Measurement of the depth and thickness of different types of BCC neoplasms with OCT exhibited excellent correlation with histopathological measurement (Olmedo et al 2007). The accuracy of OCT measurement is relatively high, typically more than $80 \%$ (Gladkova et al 2004). One limitation of OCT is that it is very difficult to differentiate inflammatory processes, cancer, and scarring with this technique (Roman Kuranov 2002). Comparing to ultrasound imaging, OCT is capable of showing very small cystic structures more distinctly. However, in terms of assessing the margins of the tumor, ultrasound is probably a better choice (Buchwald et al 2003).

\section{Ultrasound}

Since its initial appearance about 50 years ago, ultrasound has become an essential tool for medical diagnosis. It is a versatile, painless, low-risk, noninvasive procedure which can be done virtually anywhere and can be readily repeated. In dermatology, high-frequency sonography (20 MHz) and mid-frequency sonography $(7.5-15 \mathrm{MHz})$ have been well-established in the diagnostic work-up of benign and malignant diseases of the skin (Desai et al 2007; Dill-Muller and Maschke 2007). The basic modes of ultrasound include the A-mode, B-mode, and Doppler method (Dill-Muller and Maschke 2007).

At a frequency of $20 \mathrm{MHz}$, tissue penetration depth of approximately 6 to $7 \mathrm{~mm}$ can be achieved. In normal skin, the dermis is markedly echogenic and sharply demarcated from the hypoechogenic subcutaneous fat (Desai et al 2007). The fibrillar network of the dermis is responsible for its echogenicity in ultrasound (Dummer et al 1995; Lassau et al 1999; Lassau et al 1997). HFUS can readily distinguish solid lesions (eg BCCs or malignant melanomas) from cystic structures (Chin et al 2003; Schmid-Wendtner and Burgdorf 2005). Although an assertive diagnosis between malignant and benign lesions cannot be made based on HFUS alone, the lesion margins can be outlined (Desai et al 2007; Milner et al 1997; Schafer-Hesterberg et al 2007). Cancerous skin tissue, such as BCC, has special friability which can cause decreased signal penetration of HFUS. Therefore, BCCs typically appear more hypoechogenic than the normal skin tissue. Due to its noninvasive, easily repeatable nature, HFUS has been used for evaluating the therapeutic efficacy of photodynamic therapy of BCC (Moore and Allan 2003).

In melanoma patients, the primary lesion is close to the skin surface which makes it a desirable target for HFUS examination (Choi and Gershenwald 2007; Lassau et al 2007). HFUS can image primary cutaneous melanomas, uveal melanomas, and the regional lymph nodes draining the skin that lie in the axilla, groin, neck and other locations. Although ultrasound study of primary melanomas in the skin and eye has provided some useful insights, the major role of ultrasound in melanoma diagnosis is to provide early detection of regional lymph node metastases (King 2006; Schafer-Hesterberg et al 2007; Uren et al 2007). HFUS is clearly superior to palpation of the nodes during follow-up and, when combined with guided fine-needle biopsy, allows for the earliest possible surgical intervention for regional nodal metastases. The use of ultrasound contrast agents may further improve the sensitivity of ultrasound in the detection of very small metastatic tumor foci (Lassau et al 2007; Uren et al 2007).

Consistency between histology and HFUS results, as well as the statistical correlation between these techniques, has been well documented (Clement et al 1998; Harland et al 1993; Jovanovic et al 2005; Lassau et al 1997; Milner et al 1997). HFUS is certainly not going to replace histology in the evaluation of skin cancer, however it can be a very useful adjunct in the surgical planning. HFUS enables live, 3-D analysis of the tumor, allowing for the in-depth examination of a skin cancer far beyond what the naked eye (or CM) can visualize, whereas histological analysis can only offer a 2-D view of the biopsied tissue sample.

\section{Terahertz pulsed imaging}

Recently, terahertz technology has become a new tool for material characterization which may also serve as a potential 
tool for disease diagnosis (Fitzgerald et al 2002; Loffler et al 2002; Mogensen and Jemec 2007; Walker et al 2004). Radiation in the far infrared region of the electromagnetic spectrum, between 60 gigahertz and 4 terahertz, is called terahertz radiation. Since the energy in this frequency range excites the intermolecular interactions, such as the librational and vibrational modes of molecules, the data acquired can provide important spectroscopic information. As a coherent technique, both the amplitude and phase of the terahertz pulse can be obtained, from which the broadband absorption and refractive index of a medium can be determined respectively. Because the absorption is generally due to the chemical constituents of the medium, the specific signatures of a disease can be measured to provide diagnostic information. In addition, the refractive index of the tissue being imaged can also potentially provide images with both morphological and functional information.

TPI studies have revealed a significant difference between ex vivo BCC and healthy skin tissue with decent accuracy (17 out of 21) (Woodward et al 2003). Evidence from positron emission tomography (PET) and MRI studies has indicated that tumors have increased water content (Bruehlmeier et al 2003; Chen et al 1992). With strong absorption across the entire terahertz range (Ueno and Ajito 2008), the changes in water content can provide a source of image contrast. In one study, TPI analysis of 18 BCC tissues both in vivo and ex vivo revealed contrast in all TPI images which correlated well with histology (Wallace et al 2004). Although the diagnostic accuracy of TPI is quite satisfactory, it can not discriminate various skin cancer subtypes therefore can not differentiate the benign lesions from the malignant ones. Overall, TPI may help surgery planning in the future, yet there is still a long way to go before its clinical application.

\section{Magnetic resonance imaging}

MRI makes use of the magnetic properties of proton or other nuclei to generate high-resolution images. The major advantage of MRI over most other imaging modalities is the exquisite soft tissue contrast with good spatial resolution $(<100 \mu \mathrm{m})$. However, the major disadvantage is the low sensitivity which typically requires long scanning time even with the use of exogenous contrast agents.

Because of its superb soft tissue contrast, MRI can readily reveal the anatomical abnormality of skin tumors to obtain morphologic information about the shape, depth, and location of the tumor (Rajeswari et al 2003). MRI is a good but comparatively expensive tool for therapy planning in skin cancers such as BCC, SCC, and Kaposi's sarcoma (Guy et al 1994; Peters and Vejlsgaard 1992). In melanoma, MRI can produce distinctive MR characteristics because of the presence of blood products and melanin. Approximately half of the melanoma metastases are hyperintense on T1-weighted images before the administration of gadolinium, whereas the cerebral metastases rarely demonstrate T1 hyperintensity (Choi and Gershenwald 2007; Garbe and Eigentler 2007; Moulin-Romsee et al 2008).

MRI can also be used for evaluating the therapeutic response of melanoma and BCC (Buijs et al 2008; Rupprecht et al 2007). The apparent diffusion coefficient calculated from diffusion-weighted MRI has become a promising biomarker for tumor response to therapy (Vossen et al 2006). Measuring the mobility of water can reveal the status of the tumor tissue in that viable tissue restricts water mobility due to the intact cell membrane, while the necrotic tissue has higher membrane permeability which results in an increased diffusion coefficient. With this technology, we can monitor the responses of skin cancers to chemotherapy or radiotherapy with high efficiency and convenience which can facilitate further optimization of the therapeutic strategy.

In summary, the cross-sectional MRI of disease extent in skin cancer is quite accurate which can give the clinician adequate information regarding the type and extent of surgery required. Not only can MRI provide diagnostic information, it can also indicate the outcome of therapeutic intervention.

\section{Other anatomical imaging techniques}

Besides the abovementioned modalities, several other imaging methods still at the early stages of development are also suitable for skin-related imaging. These techniques include fluorescence remission sensoring (Wollina et al 2007), Raman spectroscopy (Lieber et al 2008; Naito et al 2008), and photoacoustic microscopy (Zhang et al 2006). Fluorescence remission sensoring was applied in a preliminary study to differentiate the subtypes of NMSC (Wollina et al 2007). Some differences were observed between BCC and actinic keratoses, which may aid in the accurate diagnosis of skin cancer (Wollina et al 2007). Raman spectroscopy has also been applied, using near-infrared (NIR, 700-900 nm) excitation, to evaluate the skin structure (Lieber et al 2008; Naito et al 2008). Functional photoacoustic microscopy was used to image angiogenesis of melanoma in vivo (Zhang et al 2006), which could give not only anatomical information but also certain functional characteristics of the diseased tissue.

Noninvasive anatomical imaging has become an indispensable tool for skin cancer diagnosis, in addition 
to conventional biopsy. Imaging can give (whole body) readout in an intact system which is much more relevant and reliable than in vitro/ex vivo assays; provide more statistically accurate results since longitudinal studies can be performed in the same subjects which serves as its own control; aid in lesion detection in cancer patients and patient stratification; and help in individualized anti-cancer treatment monitoring and dose optimization. Each of these anatomical imaging techniques has its advantages and disadvantages (Table 1). Although they can be very helpful in many settings, anatomical imaging alone is not sufficient to guide diagnosis and therapy since the biological/molecular changes occur long before any anatomical differences can be detected. In the following text, we will summarize the current state-of-the-art of molecular imaging of skin cancer, which can give pivotal information about the biological/molecular changes in an intact system.

\section{Molecular imaging of skin cancer}

The field of molecular imaging, recently defined by the Society of Nuclear Medicine (SNM) to be "the visualization, characterization and measurement of biological processes at the molecular and cellular levels in humans and other living systems" (Mankoff 2007), has flourished over the last decade. In general, molecular imaging modalities include molecular MRI (mMRI), magnetic resonance spectroscopy (MRS), optical bioluminescence, optical fluorescence, targeted ultrasound, single photon emission computed tomography (SPECT), and PET (Massoud and Gambhir 2003). Continued development and wider availability of scanners dedicated to small animal imaging studies, which can provide a similar in vivo imaging capability in mice, primates, and humans, can enable smooth transfer of knowledge and molecular measurements between species thereby facilitating clinical translation.

Molecular imaging takes advantage of the traditional diagnostic imaging techniques and introduces molecular imaging agents (probes) to determine the expression of indicative molecular markers at different stages of diseases. A molecular imaging agent, defined as "a probe used to visualize, characterize, and measure biological processes in living systems" (Mankoff 2007), is typically composed of an imaging label, a carrier that contains (a) targeting ligand(s) or is a targeting ligand, and a linker between the carrier and the label. Many factors need to be optimized simultaneously to obtain the best imaging outcome. Noninvasive detection of the molecular markers can allow for much earlier diagnosis, earlier treatment, and better prognosis that will eventually lead to personalized medicine.

Most of the molecular imaging studies of skin cancer targets melanoma since it is highly metastatic and is the most deadly disease among all skin cancer subtypes. The molecular pathway/targets that have been investigated include glucose metabolism, integrin $\alpha_{\mathrm{v}} \beta_{3}$, melanocortin-1 receptor (MC1R), high molecular weight melanoma-associated antigen (HMWA), and several others.

\section{Imaging glucose metabolism}

PET, a radionuclide-based imaging technique, has been used for the diagnosis, staging, and restaging after treatment or recurrence of various cancer types including melanoma (Kumar and Alavi 2005). The increased metabolism of glucose in malignant viable cells makes ${ }^{18} \mathrm{~F}$-fluorodeoxyglucose $\left({ }^{18} \mathrm{~F}-\mathrm{FDG}\right.$, Figure 2$)$ the most commonly used PET radiopharmaceuticals (Gambhir et al 2001). Like glucose, ${ }^{18} \mathrm{~F}-\mathrm{FDG}$ is transported into the tumor

Table I Comparison of the anatomical imaging modalities that have been used for skin cancer diagnosis

\begin{tabular}{|c|c|c|c|c|c|}
\hline & CM & OCT & HFUS & TPI & MRI \\
\hline Resolution & $\mathrm{I}-5 \mu \mathrm{m}$ & $2-20 \mu \mathrm{m}$ & $50-300 \mu \mathrm{m}$ & $20-200 \mu \mathrm{m}$ & $25-100 \mu \mathrm{m}$ \\
\hline Penetration & $\sim 250 \mu \mathrm{m}$ & $\mathrm{I}-3 \mathrm{~mm}$ & $6-7 \mathrm{~mm}$ & $\begin{array}{l}\text { Frequency dependent } \\
\text { (typically }<1 \mathrm{~mm} \text { ) }\end{array}$ & no limit \\
\hline Diagnosis accuracy & +++ & ++ & ++ & + & +++ \\
\hline Contrast agent? & not needed & not needed & sometimes & not needed & sometimes \\
\hline Spectra used & near-infrared & infrared & around $20 \mathrm{MHz}$ & terahertz wave & radiowaves \\
\hline Major advantages & $\begin{array}{l}\text { high resolution, fast, } \\
\text { real-time imaging }\end{array}$ & $\begin{array}{l}\text { high resolution, } \\
\text { cross-sectional } \\
\text { imaging }\end{array}$ & $\begin{array}{l}\text { easy to use, wide } \\
\text { availability, allow } \\
\text { 3-D imaging }\end{array}$ & $\begin{array}{l}\text { both morphological } \\
\text { and functional }\end{array}$ & $\begin{array}{l}\text { high accuracy, exquisite } \\
\text { tissue contrast }\end{array}$ \\
\hline Major disadvantages & $\begin{array}{l}\text { limited penetration, } \\
\text { small field-of-view, } \\
\text { extensive training }\end{array}$ & $\begin{array}{l}\text { hard to distinguish } \\
\text { tumor from scar } \\
\text { or inflammation }\end{array}$ & $\begin{array}{l}\text { relatively low } \\
\text { resolution and } \\
\text { penetration }\end{array}$ & $\begin{array}{l}\text { limited availability, } \\
\text { not fully validated }\end{array}$ & $\begin{array}{l}\text { expensive, low sensitivity, } \\
\text { slow acquisition }\end{array}$ \\
\hline
\end{tabular}



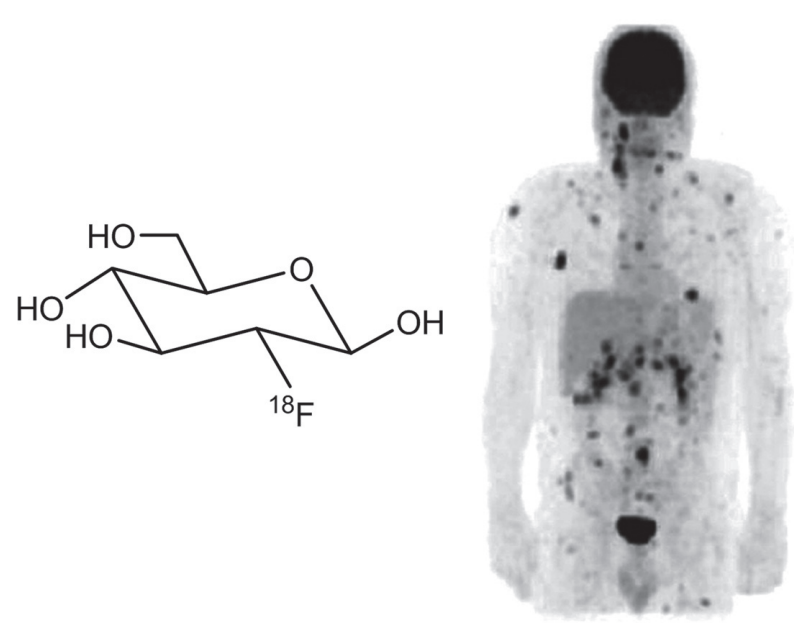

Figure 2 The chemical structure of ${ }^{18} \mathrm{~F}-\mathrm{FDG}$ and a PET scan showing extensive metastatic lesions (dark spots) of a melanoma patient. Adapted from (Belhocine et al 2006).

cells by glucose transporters. After phosphorylation by hexokinase, the ${ }^{18} \mathrm{~F}$-FDG-6-phosphate is trapped inside the cell (which gives tumor contrast) because it is not a substrate for glucose-6-phosphate isomerase. Since there is usually many-fold increase in glucose metabolism in malignant tumors as compared with the normal tissue, ${ }^{18} \mathrm{~F}-\mathrm{FDG}$ PET has been extensively explored for cancer imaging (Gambhir et al 2001).

In 1991, the finding that ${ }^{18} \mathrm{~F}-\mathrm{FDG}$ can be preferentially taken up in murine melanoma xenografts eventually led to the use of ${ }^{18} \mathrm{~F}$-FDG PET in melanoma patient management (Wahl et al 1990a). ${ }^{18} \mathrm{~F}$-FDG PET has since been studied in many different scenarios in melanoma patients. For initial staging of melanoma, ${ }^{18} \mathrm{~F}-\mathrm{FDG}$ PET has lower sensitivity than sentinel lymph node (SLN) biopsy, therefore it cannot replace SLN biopsy for regional lymph node staging (Acland et al 2001; Hafner et al 2004; Macfarlane et al 1998). Since melanoma can metastasize widely into various organs and tissues (Rusciano 2000; Streit and Detmar 2003), currently ${ }^{18} \mathrm{~F}-\mathrm{FDG}$ PET is most commonly used for suspected or known distant metastases in patients with melanoma (Figure 2) (Belhocine et al 2006). It has been shown that ${ }^{18} \mathrm{~F}$-FDG PET is more accurate than conventional modalities such as computed tomography, MRI, ultrasound, and physical examination for determination of the presence and extent of metastatic diseases (Finkelstein et al 2004; Swetter et al 2002). Because ${ }^{18} \mathrm{~F}$-FDG PET is highly sensitive and specific for the detection of metastatic melanoma thereby guiding the therapeutic planning, it can be used for surveillance after treatment in patients with high-risk stage III and IV melanoma (Delbeke 1999; Fuster et al 2004; Macapinlac 2004).
Aside from the tumor tissue, ${ }^{18} \mathrm{~F}-\mathrm{FDG}$ can also have significant uptake in other sites such as inflammatory tissue and the brown fat which may lead to false positives. Moreover, since the increased accumulation of ${ }^{18} \mathrm{~F}-\mathrm{FDG}$ in melanoma cells is due to a higher metabolic rate than the normal cells, ${ }^{18} \mathrm{~F}-\mathrm{FDG}$ is not a melanoma-specific imaging agent per se. Many other molecular targets or strategies have also been investigated for molecular imaging of melanoma.

\section{Imaging integrin $\alpha_{v} \beta_{3}$}

Integrins, a family of cell adhesion molecules, are involved in a wide range of cell-extracellular matrix and cell-cell interactions (Brooks et al 1994; Hood and Cheresh 2002). Integrins expressed on endothelial cells modulate cell migration and survival during angiogenesis while integrins expressed on carcinoma cells potentiate metastasis by facilitating invasion and movement across blood vessels. Each integrin molecule is consisted of noncovalently associated $\alpha$ and $\beta$ subunits and at least 24 different integrins have been identified (Ruoslahti 1996; Xiong et al 2001). The $\alpha_{v} \beta_{3}$ integrin, which binds to Arginine-Glycine-Aspartic acid (RGD)-containing components of the interstitial matrix (eg vitronectin, fibronectin and thrombospondin), is significantly upregulated on endothelium during angiogenesis but not in quiescent endothelium (Brooks et al 1994; Hood and Cheresh 2002). It is expressed in a wide variety of cancer types including melanoma. By activating and controlling many signaling pathways, integrin $\alpha_{v} \beta_{3}$ can enable melanoma cells to transform from stationary to a migratory and invasive phenotype (Kuphal et al 2005; Seftor 1998). Several molecular imaging agents targeting integrin $\alpha_{v} \beta_{3}$ have been tested in animal models of skin cancer, one of which has already entered clinical development.

A ${ }^{125}$ I-labeled monomeric RGD peptide, c(RGDyV), was found to undergo predominately hepatobiliary excretion in an integrin $\alpha_{\mathrm{v}} \beta_{3}$-positive M21 melanoma xenograft model (Haubner et al 1999). Therefore, glycosylated RGD-containing peptides were prepared to reduce the live uptake. Subsequently, a glycopeptide based on another peptide sequence, c(RGDfK), was labeled with ${ }^{18} \mathrm{~F}$ via a $2-{ }^{18} \mathrm{~F}$-fluoropropionate $\left({ }^{18} \mathrm{~F}-\mathrm{FPA}\right)$ prosthetic group and the resulting ${ }^{18} \mathrm{~F}$-galacto-RGD (Figure 3) exhibited receptor specific tumor uptake in the M21 melanoma model (Haubner et al 2001). This tracer was found to be quite stable in vivo. The intact fraction of ${ }^{18} \mathrm{~F}$-galacto-RGD in the mouse blood, liver, kidney, and tumor was approximately $87 \%, 76 \%, 69 \%$, and $87 \%$, respectively at $2 \mathrm{~h}$ post-injection. (Haubner et al 2004b). 


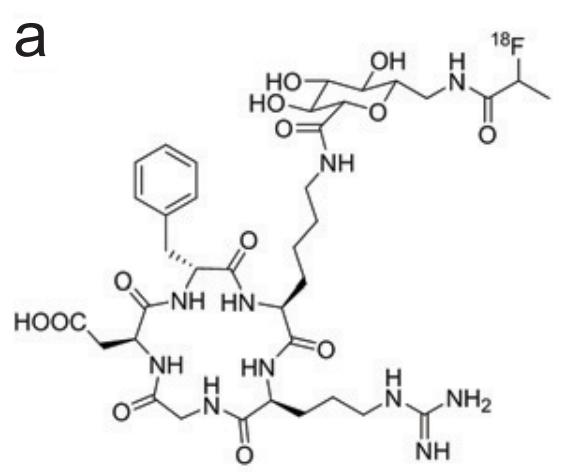

${ }^{18} \mathrm{~F}$-galacto-RGD
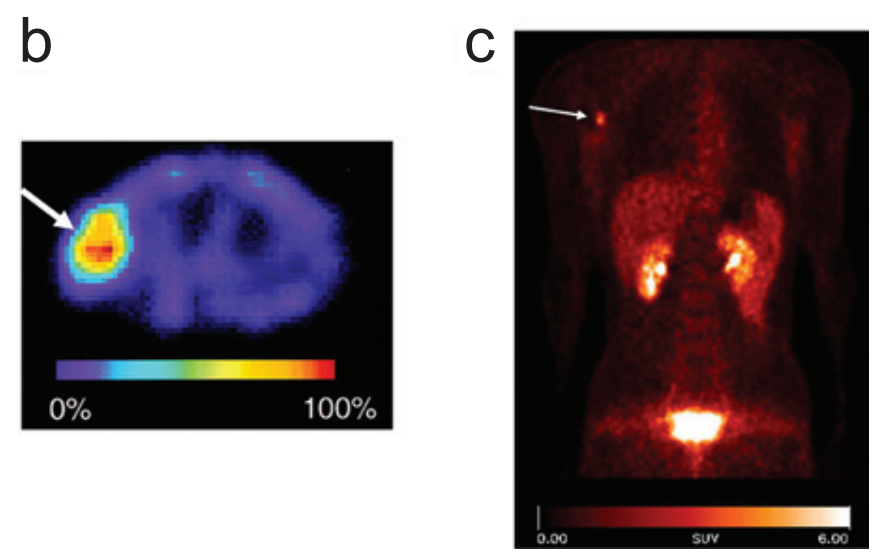

Figure $3{ }^{18} \mathrm{~F}$-galacto-RGD has been evaluated both preclinically and in melanoma patients. a) The chemical structure of ${ }^{18} \mathrm{~F}$-galacto-RGD. b) The transaxial PET image of a nude mouse bearing a M2I human melanoma tumor (arrow) at 90 min post-injection. c) A patient with stage Illb malignant melanoma and a solitary lymph node metastasis in the right axilla (arrow) was visualized by ${ }^{18} \mathrm{~F}$-galacto-RGD. Adapted from (Haubner et al 2005).

${ }^{18} \mathrm{~F}$-galacto-RGD has since been evaluated in the clinic and several studies have been reported, many of which involves melanoma patients. Initial study with nine patients of various tumor types revealed rapid, predominantly renal excretion of the tracer, resulting in fast tracer elimination from the blood and low tracer concentration in most of the organs (Haubner et al 2005). In tumor lesions, tracer accumulation showed great heterogeneity, with the standardized uptake values (SUVs) ranging from 1.2 to 10.0 (Figure 3). Subsequently, the biodistribution, pharmacokinetics, and human dosimetry of ${ }^{18} \mathrm{~F}$-galacto-RGD was evaluated in groups of cancer patients including melanoma (Beer et al 2005; Beer et al 2006b). Reversed-phase high-performance liquid chromatography (RP-HPLC) of human serum revealed that more than $95 \%$ of tracer was intact up to $2 \mathrm{~h}$ post-injection and the highest absorbed radiation dose was in the bladder wall $(8.14 \pm 1.11 \mathrm{mGy} / \mathrm{mCi})$, due to primarily renal excretion of the tracer. In another study, patients with solid tumors were examined with ${ }^{18} \mathrm{~F}$-galacto-RGD PET before surgical removal of the tumor lesions (Beer et al 2006a). Snap-frozen specimens were collected from representative areas with low and intense SUV of ${ }^{18} \mathrm{~F}$-galacto-RGD for immunohistochemistry. The SUV value of the tumor ranges from 0.4 to 10.0 and there was a significant correlation of SUV or the tumor/blood ratio with the intensity of immunohistochemical staining as well as with the microvessel density. These results suggested that ${ }^{18} \mathrm{~F}$-galacto-RGD PET might be used as a new marker of angiogenesis and for individualized planning of therapeutic intervention.

Besides PET, various other modalities have been used for integrin $\alpha_{v} \beta_{3}$ imaging in small animal skin cancer models. An ${ }^{111}$ In-labeled nonpeptidic integrin $\alpha_{\mathrm{v}} \beta_{3}$ antagonist and a ${ }^{99 m}$ Tc-labeled RGD analogue has been evaluated for the visualization of $\alpha_{v} \beta_{3}$ integrin expression in nude mice bearing M21 melanoma tumors (Haubner et al 2004a; Jang et al 2007). However, the pharmacokinetics and metabolic stability of the tracers was unsatisfactory for potential clinical application. Fluorescent dye conjugated RGD peptide has also been tested in M21 tumor models (Wang et al 2004). Only minimal difference of fluorescence intensity was observed between the M21 and M21-L (integrin $\alpha_{\mathrm{v}} \beta_{3}$-negative) melanoma tumors. Peptidomimetic integrin $\alpha_{\mathrm{v}} \beta_{3}$ antagonist conjugated magnetic nanoparticles were tested in athymic nude mice bearing human melanoma tumors (Schmieder et al 2005). Very small regions (about $30 \mathrm{~mm}^{3}$ ) of angiogenesis associated with nascent melanoma tumors were visualized by this technique, which may potentially enable phenotyping and staging of early melanoma in a clinical setting.

Recently, cyanoacrylate microbubbles linked to multiple targeting ligands were employed to investigate the changes in molecular cancer marker expression during MMP inhibitor treatment in a HaCaT-ras-A-5RT3 SCC xenograft model (Palmowski et al 2008). One type of the ligand can bind to vascular endothelial growth factor receptor 2 (VEGFR-2) and the other type binds to $\alpha_{v} \beta_{3}$ integrin. Multi-marker imaging, achieved during the same imaging session, indicated a significant increase of VEGFR-2 and $\alpha_{v} \beta_{3}$ integrin expression during tumor angiogenesis, as well as a considerable decrease in the density of both markers after treatment. This study suggested that targeted ultrasound may be feasible for longitudinal molecular profiling of tumor angiogenesis and sensitive assessment of anti-angiogenic cancer therapy in vivo. 
Dualmodality agents for both SPECT and optical imaging of $\alpha_{\mathrm{v}} \beta_{3}$ integrin expression have been reported. c(RGDfK) was labeled with ${ }^{111}$ In and IRDye800 (emission maximum: $800 \mathrm{~nm}$ ) for gamma scintigraphy and continuous-wave imaging of M21 melanoma xenografts, respectively (Houston et al 2005). Twenty-four hours after administration of the agent at a dose equivalent to $90 \mu \mathrm{Ci}$ of ${ }^{111} \mathrm{In}$ and $5 \mathrm{nmol}$ of the NIR dye, whole-body gamma scintigraphy and optical imaging was conducted. It was found that while the target-to-background ratios of gamma scintigraphy and optical imaging were similar for superficial tumors, the signal-to-noise ratio (SNR) was significantly higher for optical than radionuclide imaging. Analysis of SNR versus contrast also showed that optical imaging has greater sensitivity for the subcutaneous tumor targets. However, such advantage quickly diminishes when the tissue of interest gets deeper under the skin ( $>$ a few $\mathrm{mm}$ ). This proof-of-principle study demonstrated for the first time the direct comparison of optical and planar radionuclide imaging for superficial and sub-surface tumors. In another report, dualmodality fluorescence and photoacoustic tomography imaging, using an integrin $\alpha_{v} \beta_{3}$-targeted peptide-dye conjugate in the M21 xenograft model, enabled simultaneous visualization of the tumor location, angiogenesis, and the brain structure (Wang et al 2005).

Imaging integrin $\alpha_{\mathrm{v}} \beta_{3}$ expression is one of the most vibrant fields of molecular imaging over the last 5 years (Cai and Chen 2008; Cai et al 2005; Cai et al 2008; Cai et al 2006). Since integrin is expressed not only in melanoma but also in many other tumor types (eg prostate, breast, brain and lung cancer), these integrin $\alpha_{\mathrm{v}} \beta_{3}$-targeted agents can have broad application in cancer patient management in general. To date, very few of these agents have entered clinical development (Bach-Gansmo et al 2006; Haubner et al 2005; Kenny et al 2008; Sivolapenko et al 1998). Much future research effort (eg, moving more promising PET tracers into clinical evaluation in a timely manner) will be needed to achieve better sensitivity/specificity in lesion (mainly metastatic melanoma) detection based on integrin $\alpha_{v} \beta_{3}$ imaging of skin cancer patients.

\section{Imaging melanocortin-I receptor}

Melanocortin-1 receptor (MC1R), overexpressed in melanomas, is a promising melanoma-specific target for molecular imaging applications (Healy 2004; Sturm et al 2003). To date, five melanocortin receptors (MC1R to MC5R) have been identified and cloned (Mountjoy et al 1992). More than $80 \%$ of human metastatic melanoma tumor

samples have been found to express MC1R (Tatro et al 1992). Radiolabeled alpha-melanocyte stimulating hormone $(\alpha-\mathrm{MSH})$ peptide analogues exhibit nanomolar MC1R binding affinities, making them promising melanoma-specific imaging probes for lesion detection.

Two types of radiolabeled $\alpha$-MSH peptides, linear and metal-cyclized, have been extensively studied (Miao and Quinn 2007). Currently, the most widely used linear $\alpha$-MSH peptide analogue is ${ }^{125} \mathrm{I}-\left[\mathrm{Nle}^{4}, \mathrm{D}-\mathrm{Phe}^{7}\right]-\alpha-\mathrm{MSH}$, often referred to as a "gold" standard due to its sub-nanomolar receptor binding affinity (Chen et al 2000). Over the last decade, various $\alpha$-MSH peptides have been radiolabeled with a dazzling number of different radionuclides including ${ }^{18} \mathrm{~F}$ (Figure 4) (Cheng et al 2007b; Vaidyanathan and Zalutsky 1997), ${ }^{99 m}$ Tc (Chen et al 2002; Chen et al 1999; Giblin et al 1998; Miao et al 2007a), ${ }^{111}$ In (Bagutti et al 1994; Chen et al 2002; Chen et al 2001; Cheng et al 2002; Froidevaux et al 2005; Froidevaux et al 2002; Miao et al 2007a; Miao et al 2008b; Newton et al 2007), ${ }^{125}$ I (Chen et al 1999; Cheng et al 2004), ${ }^{67} \mathrm{Ga}$ (Froidevaux et al 2004; Wei et al 2007b), ${ }^{68} \mathrm{Ga}$ (Froidevaux et al 2004; Wei et al 2007b), ${ }^{86} \mathrm{Y}$ (McQuade et al 2005), ${ }^{64} \mathrm{Cu}$ (Cheng et al 2007a;

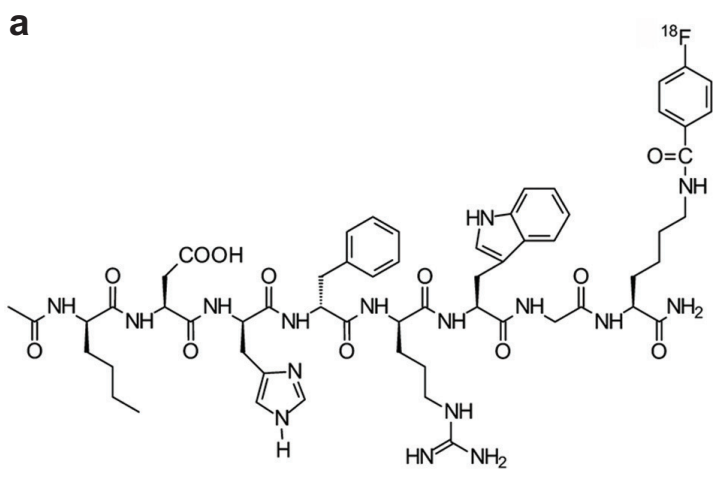

b

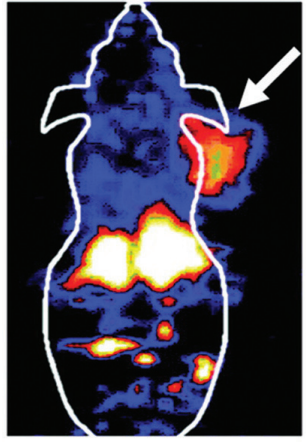

High MC1R

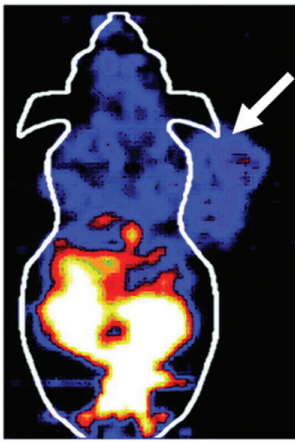

Low MC1R

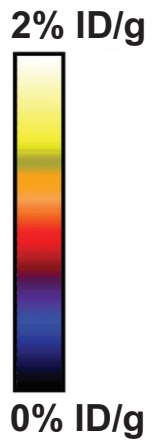

$0 \% \mathrm{ID} / \mathrm{g}$

Figure 4 PET imaging of MCIR expression using an ${ }^{18} \mathrm{~F}$-labeled $\alpha-M S H$ analog. a) The chemical structure of the PET tracer. b) Decay-corrected coronal PET images of mice bearing BI6FI0 (high MCIR expression) or A375M (low MCIR expression) melanoma tumor (arrows) at I h post-injection. Adapted from (Cheng et al 2007b). 
McQuade et al 2005; Wei et al 2007a), ${ }^{186}$ Re (Giblin et al 1997), ${ }^{203} \mathrm{~Pb}$ (Miao et al 2008a), ${ }^{188} \mathrm{Re}$ (Giblin et al 1998; Miao et al 2005c; Miao et al 2003), ${ }^{90} \mathrm{Y}$ (Miao et al 2006; Miao et al 2005a), ${ }^{177} \mathrm{Lu}$ (Miao et al 2006; Miao et al 2005a; Miao et al 2007b), and ${ }^{212} \mathrm{~Pb}$ (Miao et al 2005b). Many of these radioisotopes are suitable for imaging only, while several others can also be used for internal radiotherapy applications.

Translating novel cancer imaging or therapeutic agents (eg, $\alpha$-MSH based radiopharmaceuticals) from bench to bedside is time-consuming and quite expensive. Multiple steps in pre-clinical development, especially the investigational new drug-directed toxicology, significantly slowed down this process. Therefore, although many of these abovementioned reports concluded/suggested that the agents developed had potential for metastatic melanoma imaging or peptide receptor-targeted radionuclide therapy, none of them have been tested yet in the clinical setting. With so many different agents developed for the same molecular target, it is rather difficult to choose the right agent for clinical evaluation. On the other hand, it is certainly impractical to evaluate several agents of similar characteristics in the clinic due to the prohibitive cost. Whether the favorable results (both imaging and therapy) observed in small animal studies will hold true in melanoma patients remains to be validated in the future.

\section{Imaging high molecular weight melanoma-associated antigen}

Tumor-associated proteoglycans of human malignant melanoma were among the earliest to be explored for imaging applications. These HMWAs range from $100 \mathrm{kDa}$ to $400 \mathrm{kDa}$ in molecular weight. More than two decades ago, ${ }^{131} \mathrm{I}$-labeled Fab fragment of an anti-HMWA antibody was tested for preliminary feasibility studies of radioimmunodetection and radioimmunotherapy of patients with inoperable metastatic melanoma (Larson et al 1985). In ten patients, 17 of 23 (74\%) documented metastases were detected by imaging with no false positives. Two patients who had avid tumor uptake subsequently received radiotherapeutic doses. Greater than $50 \%$ reduction in the size of pelvic and pericaval nodes was observed, which remained stable for three months. Although subsequent studies revealed that melanoma metastases can also be identified with either intravenous or subcutaneous injection of radiolabeled antibodies (Lotze et al 1986), the use of a Fab fragment is more advantageous than the intact antibody (IgG) because of the significantly lower uptake in liver.
${ }^{131}$ I-labeled intact antibody (225.28S) and its $\mathrm{F}\left(\mathrm{ab}^{\prime}\right)_{2}$ fragment, which recognizes HMWA, was evaluated in eight melanoma patients (Buraggi et al 1985). It was also found that the $\left.\mathrm{F}(\mathrm{ab})_{2}\right)_{2}$ fragment is superior to the intact antibody in immunoscintigraphy, since it markedly reduced the background in the bone marrow, liver, and spleen. A report of ${ }^{99 \mathrm{~m}} \mathrm{Tc}$-labeled Fab fragment of an anti-HMWA antibody in twenty patients revealed that radioimaging with this radiopharmaceutical is a sensitive test, especially for detecting liver lesions (Lamki et al 1990). Once again, it was confirmed that biodistribution and imaging sensitivity of this Fab-based tracer differ significantly from that of an ${ }^{111}$ In-labeled anti-melanoma IgG.

Several other radiolabeled monoclonal antibody $(\mathrm{mAb})$ or antibody fragments recognizing HMWAs have also been reported in preclinical studies (Hamilton et al 2001; Le Doussal et al 1990; Svec et al 1989) and clinical studies (Sergieva and Virtcheva-Genkova 1997; Wahl et al 1990b). To reduce the nonspecific uptake of radiolabeled monoclonal antibodies in normal tissues, a significant problem for tumor imaging, pre-dosing with cold, nonspecific, isotype-matched antibody before the injection of radiolabeled antibody was tested (Wahl et al 1987). Disappointingly, no decrease in tumor or normal tissue uptake was observed for either tumor-specific or nonspecific monoclonal antibodies after such pre-dosing. Therefore, high doses of isotype-matched unlabeled nonspecific $\mathrm{mAb}$ given before radiolabeled tumor-specific $\mathrm{mAb}$ will not enhance tumor imaging. The use of antibody fragments, rather than the intact antibodies, is still the preferred approach for achieving better tumor contrast.

A series of studies have been reported using ZME-018, a mouse anti-melanoma mAb. More than two decades ago, ${ }^{111}$ In-labeled ZME-018 was examined in thirty patients with metastatic malignant melanoma (Murray et al 1987). Because intact mAb was used, nonspecific uptake of radioactivity was consistently observed in the liver and spleen. It was concluded that radioimmunolocalization of melanoma with ${ }^{111}$ In-ZME-018 was feasible and the sensitivity of the technique varies with the $\mathrm{mAb}$ dose, specific activity of the tracer, tumor size, and the disease site. Another study was then carried out to evaluate the radiation dosimetry and efficacy of the ${ }^{111}$ In-labeled ZME-018 in localizing metastatic lesions (Taylor et al 1988). Imaging was able to detect the lesion in 14 of $18(78 \%)$ patients with active disease, and identify 24 of 44 (77\%) lesions greater than $1 \mathrm{~cm}$. More importantly, imaging changed or specifically directed patient management in 22\% (4/18) of the melanoma patients. Assuming a biodistribution similar to ${ }^{111} \mathrm{In}$-ZME-018, the radiation dose delivered to 
normal tissues by ${ }^{90} \mathrm{Y}$-ZME-018 would restrict its use for radioimmunotherapy although it can potentially deliver substantial tumor doses in selected patients.

ZME-018 has also been tested for delivering gelonin (a plant toxin), which was chemically conjugated to the antibody using different heterobifunctional crosslinking reagents, to antigen-positive human melanoma cells (Rosenblum et al 1999). Tissue distribution studies in tumor-bearing nude mice demonstrated that tumor uptake of the immunotoxin was similar to that of the intact antibody. Interestingly, the conjugate containing a recombinant gelonin was found to be more efficacious than those conjugates incorporating natural gelonin.

A variety of anti-HMWA antibody and antibody fragments have been evaluated for melanoma imaging (Figure 5), most of which focused on the metastatic lesions. One common finding from these studies is that the use of an intact $\mathrm{mAb}$ is not optimal for either tumor imaging or tumor therapy. One way of improving the pharmacokinetics and tissue distribution profile, as demonstrated from these reports, is to use smaller antibody fragments. We speculate that another form of
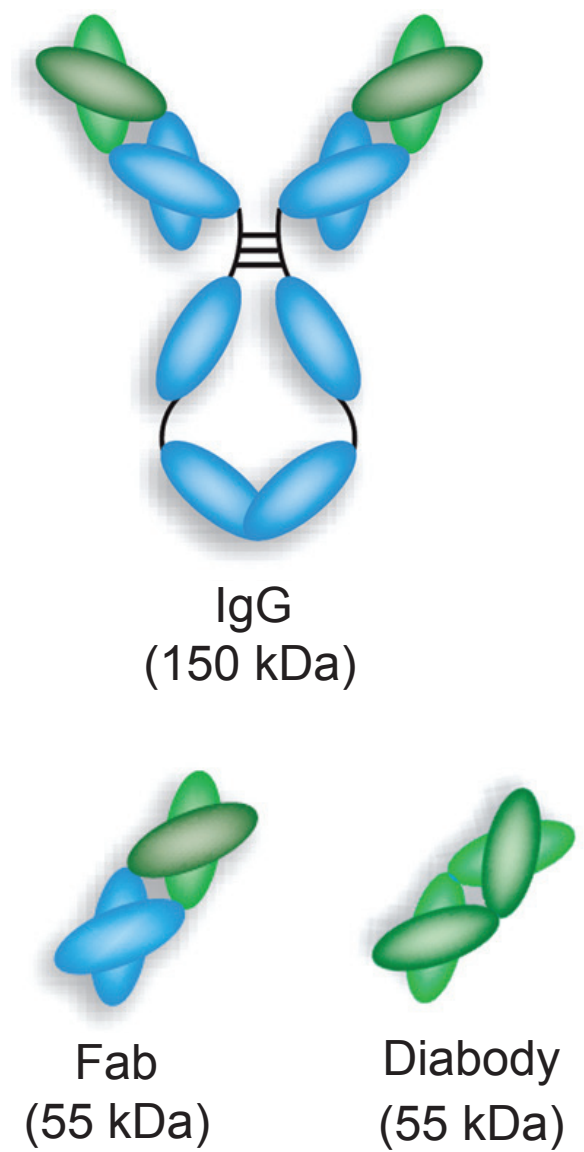
(55 kDa) antibody fragments not studied in the abovementioned reports, a diabody which has a molecular weight of about $55 \mathrm{kDa}$ (Cai et al 2007b), may be a better alternative. Not only does a diabody clears from the circulation much faster than either $\mathrm{mAb}$ or $\mathrm{F}(\mathrm{ab})_{2}$, which confers improved tumor contrast at early time points, it also preserves the bivalent antigen binding property which is more advantageous than either Fab or scFv fragments. Another approach to improve the tumor contrast is through pre-targeting, which typically requires the use of either biotinylated antibodies or bispecific antibodies (Gasparri et al 1999; Sharkey et al 2005).

\section{Other molecular targets and strategies}

A number of other agents have been investigated in animal models and melanoma patients. More than two decades ago, ${ }^{99 \mathrm{~m}} \mathrm{Tc}$-labeled Nocardia soluble peptidoglycan derivative (which can bind to a model of activated macrophages) was evaluated for scintigraphic detection of melanoma metastasis (Le Pape et al 1986). The agent was encapsulated into liposomes and administered via the respiratory tract as an aerosol to melanoma patients with either known metastases or
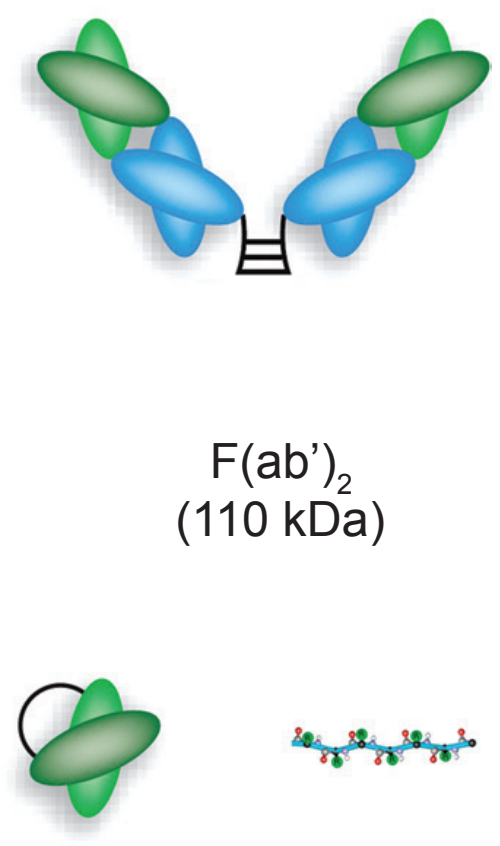

$\mathrm{scFv}$

$(28 \mathrm{kDa}) \quad(\sim 1 \mathrm{kDa})$

Figure $\mathbf{5}$ Schematic structures of intact antibody and various antibody fragments. 
patients with a high risk of recurrent melanoma. Scintigraphy a few hours later revealed very small metastases, not seen by conventional scintigraphy, which was confirmed by histology. A ${ }^{125} \mathrm{I}$ - and ${ }^{111}$ In-labeled $\mathrm{mAb}$, specific for the G(D3) antigen, was tested in melanoma xenograft models (Lee et al 2001). In vivo localization of a radiolabeled anti-G(D3) mAb to G(D3)-expressing xenografts was observed with gamma camera imaging.

Lymphoseek, a ${ }^{99 m}$ Tc-labeled mannosyl-dextran that binds to mannose-binding protein (Vera et al 2001), is a agent designed for sentinel lymph node mapping. A phase I clinical trial was conducted to compare Lymphoseek with filtered ${ }^{99 m}$ Tc-sulfur colloid (a particulate complex which can be taken up by the reticuloendothelial system) for melanoma sentinel lymph node detection in patients (Wallace et al 2007). No adverse events were observed. Further, Lymphoseek exhibited faster injection site clearance and equivalent primary sentinel node uptake than the filtered ${ }^{99 m}$ Tc-sulfur colloid.

Besides gamma camera and/or SPECT imaging, several other modalities have also been reported for imaging melanoma. MRI of human epidermal growth factor receptor 2 (HER2 (Cai et al 2007a)) and 9.2.27 tumor antigens were performed in a panel of cultured melanoma and mammary cell lines, using antibody conjugated monocrystalline iron oxide nanoparticles (Funovics et al 2004). It was found that anti -9.2 .27 conjugates bound to the plasma membrane while the anti-HER2 conjugates underwent receptor-mediated endocytosis.

A fluorescent deoxyglucose analog was reported for tumor imaging in an A375M melanoma model (Cheng et al 2006). However, both the glucose analog and a nonspecific control exhibited tumor (cell) uptake in cell culture and living mice. Such low specificity is likely due to the much larger size of the dye than the glucose analog, which significantly affects its cellular uptake by the glucose transporters and hexokinase. A ${ }^{64} \mathrm{Cu}$-labeled antibody against disialogangliosides, overexpressed in melanoma, was tested in nude mice bearing subcutaneous melanoma tumors (Voss et al 2007). The conjugate was shown to have high specific activity, antigen binding affinity, and in vivo target specificity.

A recent proof-of-concept study utilized electron paramagnetic resonance (EPR) imaging, which detects the naturally occurring free radicals in melanin pigments, for melanoma imaging (Vanea et al 2008). The potential of EPR in imaging melanoma samples was demonstrated in vitro using both animal and human samples. Upon further development and optimization, this technology may potentially advance the diagnosis of suspected melanoma lesions.

\section{Summary and outlook}

Big strides have been made in anatomical and molecular imaging of skin cancer. Although both types of imaging techniques can play a role in any skin cancer subtypes, it appears that anatomical imaging will be more useful/relevant in nonmelanoma while molecular imaging plays a more important role in melanoma and melanoma metastasis. Most of the anatomical imaging techniques do not require contrast agent, therefore much clinical data are available. On the other hand, almost all molecular imaging techniques require a molecular probe to be administered, which typically takes a long time from initial development to final approval for clinical use. Thus it is not surprising that most of the clinical data for molecular imaging of skin cancer is about PET imaging after injection of ${ }^{18} \mathrm{~F}-\mathrm{FDG}$ (the only PET agent that has gained approval for cancer imaging from the Food and Drug Administration).

Interestingly, a significant portion of the clinical data regarding molecular imaging of skin cancer (mostly melanoma) comes from about 20 years ago, although at that time the term "molecular imaging" has not been widely spread across the scientific community. The explosion of molecular imaging research over the last decade is partially, if not mostly, due to the increasingly wider availability of scanners dedicated to small animal studies. However, with an overwhelming number of animal studies reported every week, clinical translation has become more and more difficult in the United States due to many regulatory constraints. For example, $\alpha$-MSH peptide analogs have been labeled with a wide variety of radioisotopes over the last decade, yet no clinical data has been report so far. With the ultimate goal being early diagnosis and monitoring therapy in cancer patients, the current status of clinical molecular imaging is by no means satisfactory or healthy.

Many scientific societies have recently tried to work with the regulatory agencies (most notably the Food and Drug Administration) in order to reduce the prohibitively expensive requirements before initial clinical evaluation of molecular imaging agents, especially PET/SPECT agents since they are administered at doses many orders of magnitude below the pharmacologically active level. The situation will have to change over the next several years, otherwise the whole field of molecular imaging will collapse. Preclinical molecular imaging is thriving all over 
Glucose metabolism

eg ${ }^{18}$ F-FDG
Integrin $\alpha_{v} \beta_{3}$ expression

eg RGD peptides labeled with ${ }^{18} \mathrm{~F},{ }^{99 \mathrm{~m}} \mathrm{Tc}$, and dyes

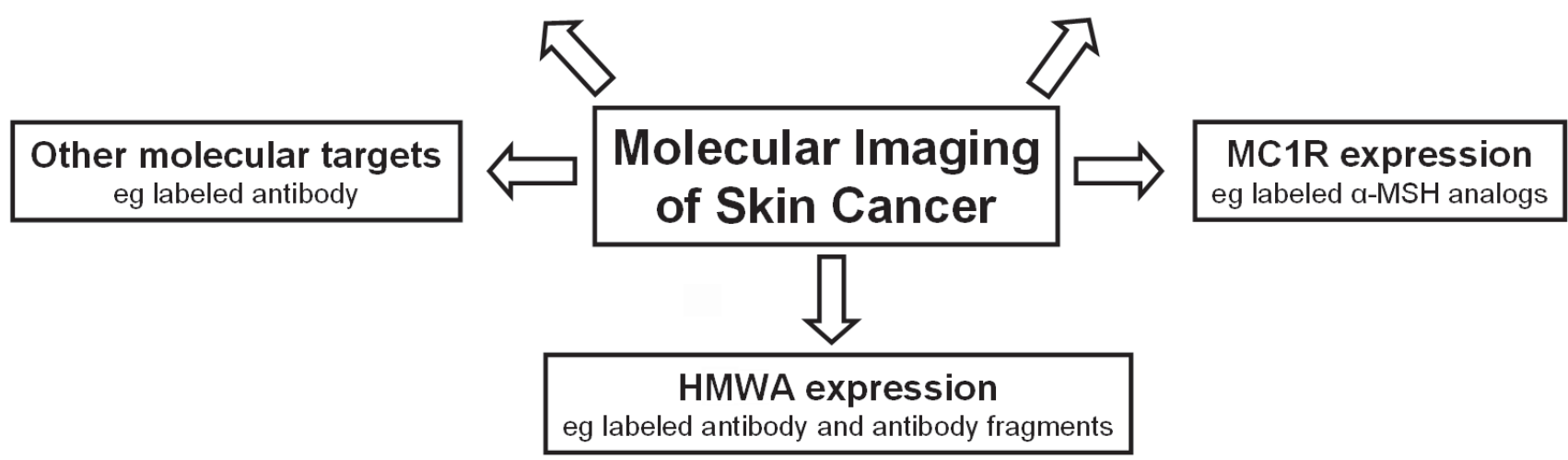

Figure 6 The various approaches towards molecular imaging of skin cancer.

the world, while clinical molecular imaging has not lived up to the expectations. It is quite discouraging that ${ }^{18} \mathrm{~F}-\mathrm{FDG}$ is still the only PET tracer approved for clinical use, at more than thirty years after the invention of the PET scanner. Many more molecular imaging agents should be evaluated in cancer patients, as ${ }^{18} \mathrm{~F}-\mathrm{FDG}$ is certainly not sufficient for melanoma detection, staging, and treatment monitoring.

It has been generally accepted that the occurrence of many cancer types depends on the life style. For example, about 90 percent of NMSCs are associated with exposure to ultraviolet radiation from the sun (Armstrong and Kricker 1993). Sunlight is the also the main environmental agent that causes melanoma, although the exact wavelengths of sunlight are currently unknown. Perhaps such is the price we have to pay for enjoying the sunshine on the beach? Studies have shown that early detection is the key to cure cancer. When the tumor is still localized to its tissue of origin, a skilled surgeon can cure a cancer patient in most cases. Metastasis is the primary killer of cancer patients, which is especially true for skin cancer where the mortality is mostly due to melanoma metastasis. With many molecular imaging agents currently in preclinical and clinical development (Figure 6), it is very likely that some of the molecularly specific agents will finally succeed in the clinic to allow for accurate early detection/diagnosis of skin cancer. The future is bright, yet many hurdles remain to be overcome and much further research/validation needs to be carried out.

\section{Disclosure}

The authors report no conflicts of interest in this work.

\section{References}

Acland KM, Healy C, Calonje E, et al. 2001. Comparison of positron emission tomography scanning and sentinel node biopsy in the detection of micrometastases of primary cutaneous malignant melanoma. J Clin Oncol, 19:2674-8.

Agero AL, Busam KJ, Benvenuto-Andrade C, et al. 2006. Reflectance confocal microscopy of pigmented basal cell carcinoma. J Am Acad Dermatol, 54:638-43.

Aghassi D, Anderson RR, and Gonzalez S. 2000. Confocal laser microscopic imaging of actinic keratoses in vivo: a preliminary report. J Am Acad Dermatol, 43:42-8.

Armstrong BK, and Kricker A. 1993. How much melanoma is caused by sun exposure? Melanoma Res, 3:395-401.

Astner S, Dietterle S, Otberg N, et al. 2008. Clinical applicability of in vivo fluorescence confocal microscopy for noninvasive diagnosis and therapeutic monitoring of nonmelanoma skin cancer. J Biomed Opt, 13:014003.

Bach-Gansmo T, Danielsson R, Saracco A, et al. 2006. Integrin receptor imaging of breast cancer: a proof-of-concept study to evaluate ${ }^{99 \mathrm{~m}}$ Tc-NC100692. J Nucl Med, 47:1434-9.

Bagutti C, Stolz B, Albert R, et al. 1994. [ ${ }^{111}$ In]-DTPA-labeled analogues of alpha-melanocyte-stimulating hormone for melanoma targeting: receptor binding in vitro and in vivo. Int J Cancer, 58:749-55.

Beer AJ, Haubner R, Goebel M, et al. 2005. Biodistribution and pharmacokinetics of the $\alpha_{\mathrm{v}} \beta_{3}$-selective tracer ${ }^{18} \mathrm{~F}$-galacto-RGD in cancer patients. J Nucl Med, 46:1333-41.

Beer AJ, Haubner R, Sarbia M, et al. 2006a. Positron emission tomography using $\left[{ }^{18} \mathrm{~F}\right]$ Galacto-RGD identifies the level of integrin $\alpha_{\mathrm{v}} \beta_{3}$ expression in man. Clin Cancer Res, 12:3942-9.

Beer AJ, Haubner R, Wolf I, et al. 2006b. PET-based human dosimetry of ${ }^{18} \mathrm{~F}$-galacto-RGD, a new radiotracer for imaging $\alpha_{\mathrm{v}} \beta_{3}$ expression. J Nucl Med, 47:763-9.

Belhocine TZ, Scott AM, Even-Sapir E, et al. 2006. Role of nuclear medicine in the management of cutaneous malignant melanoma. J Nucl Med, 47:957-67.

Brooks PC, Clark RA, and Cheresh DA. 1994. Requirement of vascular integrin $\alpha_{\mathrm{y}} \beta_{3}$ for angiogenesis. Science, 264:569-71.

Bruehlmeier M, Roelcke U, Blauenstein P, et al. 2003. Measurement of the extracellular space in brain tumors using ${ }^{76} \mathrm{Br}$-bromide and PET. J Nucl Med, 44:1210-8.

Buchwald HJ, Muller A, Kampmeier J, et al. 2003. [Optical coherence tomography versus ultrasound biomicroscopy of conjunctival and eyelid lesions]. Klin Monatsbl Augenheilkd, 220:822-9. 
Buijs M, Vossen JA, Hong K, et al. 2008. Chemoembolization of hepatic metastases from ocular melanoma: assessment of response with contrast-enhanced and diffusion-weighted MRI. AJR Am J Roentgenol, 191:285-9.

Buraggi GL, Callegaro L, Mariani G, et al. 1985. Imaging with ${ }^{131}$ I-labeled monoclonal antibodies to a high-molecular-weight melanoma-associated antigen in patients with melanoma: efficacy of whole immunoglobulin and its $\mathrm{F}(\mathrm{ab}$ '), fragments. Cancer Res, 45:3378-87.

Cai W, and Chen X. 2008. Multimodality imaging of tumor angiogenesis. J Nucl Med, 49:113S-28S.

Cai W, Gambhir SS, and Chen X. 2005. Multimodality tumor imaging targeting integrin $\alpha_{v} \beta_{3}$. Biotechniques, 39:S6-S17.

Cai W, Niu G, and Chen X. 2007a. Multimodality imaging of the HER-kinase axis in cancer. Eur J Nucl Med Mol Imaging, 35:186-208.

Cai W, Niu G, and Chen X. 2008. Imaging of integrins as biomarkers for tumor angiogenesis. Curr Pharm Des, in press.

Cai W, Olafsen T, Zhang X, et al. 2007b. PET imaging of colorectal cancer in xenograft-bearing mice by use of an ${ }^{18} \mathrm{~F}$-labeled T84.66 anti-carcinoembryonic antigen diabody. $J$ Nucl Med, 48:304-10.

Cai W, Rao J, Gambhir SS, et al. 2006. How molecular imaging is speeding up anti-angiogenic drug development. Mol Cancer Ther, 5:2624-33.

Campbell FA, and Campbell C. 2006. Magnetic resonance imaging for stage IV melanoma during pregnancy. Arch Dermatol, 142:393.

Carless MA, and Griffiths LR. 2008. Cytogenetics of melanoma and nonmelanoma skin cancer. Adv Exp Med Biol, 624:227-40.

Chen J, Cheng Z, Hoffman TJ, et al. 2000. Melanoma-targeting properties of $(99 \mathrm{~m})$ technetium-labeled cyclic alpha-melanocyte-stimulating hormone peptide analogues. Cancer Res, 60:5649-58.

Chen J, Cheng Z, Miao Y, et al. 2002. Alpha-melanocyte-stimulating hormone peptide analogs labeled with technetium-99 $\mathrm{m}$ and indium-111 for malignant melanoma targeting. Cancer, 94:1196-201.

Chen J, Cheng Z, Owen NK, et al. 2001. Evaluation of an ${ }^{111}$ In-DOTA-rhenium cyclized alpha-MSH analog: a novel cyclic-peptide analog with improved tumor-targeting properties. $J$ Nucl Med, 42:1847-55.

Chen J, Giblin MF, Wang N, et al. 1999. In vivo evaluation of ${ }^{99 \mathrm{~m}} \mathrm{Tc} /{ }^{188} \mathrm{Re}$-labeled linear alpha-melanocyte stimulating hormone analogs for specific melanoma targeting. Nucl Med Biol, 26:687-93.

Chen JH, Avram HE, Crooks LE, et al. 1992. In vivo relaxation times and hydrogen density at $0.063-4.85 \mathrm{~T}$ in rats with implanted mammary adenocarcinomas. Radiology, 184:427-34.

Cheng Z, Chen J, Miao Y, et al. 2002. Modification of the structure of a metallopeptide: synthesis and biological evaluation of ${ }^{111} \mathrm{In}$-labeled DOTA-conjugated rhenium-cyclized alpha-MSH analogues. $J$ Med Chem, 45:3048-56.

Cheng Z, Chen J, Quinn TP, et al. 2004. Radioiodination of rhenium cyclized alpha-melanocyte-stimulating hormone resulting in enhanced radioactivity localization and retention in melanoma. Cancer Res, 64:1411-8.

Cheng Z, Levi J, Xiong Z, et al. 2006. Near-infrared fluorescent deoxyglucose analogue for tumor optical imaging in cell culture and living mice. Bioconjug Chem, 17:662-9.

Cheng Z, Xiong Z, Subbarayan M, et al. 2007a. ${ }^{64} \mathrm{Cu}$-labeled alpha-melanocyte-stimulating hormone analog for microPET imaging of melanocortin 1 receptor expression. Bioconjug Chem, $18: 765-72$

Cheng Z, Zhang L, Graves E, et al. 2007b. Small-animal PET of melanocortin 1 receptor expression using a $18 \mathrm{~F}$-labeled alpha-melanocyte-stimulating hormone analog. J Nucl Med, 48:987-94.

Chin K, Finger PT, and Iacob C. 2003. High-frequency ultrasound imaging of periocular hidrocystomas. Optometry, 74:760-4.

Choi EA, and Gershenwald JE. 2007. Imaging studies in patients with melanoma. Surg Oncol Clin N Am, 16:403-30.

Clement A, Fayet P, Hoeffel C, et al. 1998. Value of high-frequency $(20 \mathrm{MHz})$ in the diagnosis of cutaneous tumors. J Radiol, 79:313-7.

Crowson AN. 2006. Basal cell carcinoma: biology, morphology and clinical implications. Mod Pathol, 19 (Suppl 2):S127-47.
Delbeke D. 1999. Oncological applications of FDG PET imaging: brain tumors, colorectal cancer, lymphoma and melanoma. J Nucl Med, 40:591-603

Desai TD, Desai AD, Horowitz DC, et al. 2007. The use of high-frequency ultrasound in the evaluation of superficial and nodular basal cell carcinomas. Dermatol Surg, 33:1220-7.

Dill-Muller D, and Maschke J. 2007. Ultrasonography in dermatology. J Dtsch Dermatol Ges, 5:689-707.

Douglas JL, Gustin JK, Dezube B, et al. 2007. Kaposi's sarcoma: a model of both malignancy and chronic inflammation. Panminerva Med, 49:119-38.

Dummer W, Blaheta HJ, Bastian BC, et al. 1995. Preoperative characterization of pigmented skin lesions by epiluminescence microscopy and high-frequency ultrasound. Arch Dermatol, 131:279-85.

Finkelstein SE, Carrasquillo JA, Hoffman JM, et al. 2004. A prospective analysis of positron emission tomography and conventional imaging for detection of stage IV metastatic melanoma in patients undergoing metastasectomy. Ann Surg Oncol, 11:731-8.

Fitzgerald AJ, Berry E, Zinovev NN, et al. 2002. An introduction to medical imaging with coherent terahertz frequency radiation. Phys Med Biol, 47:R67-84.

Froidevaux S, Calame-Christe M, Schuhmacher J, et al. 2004. A gallium-labeled DOTA-alpha-melanocyte-stimulating hormone analog for PET imaging of melanoma metastases. J Nucl Med, 45:116-23.

Froidevaux S, Calame-Christe M, Tanner H, et al. 2002. A novel DOTA-alpha-melanocyte-stimulating hormone analog for metastatic melanoma diagnosis. $J$ Nucl Med, 43:1699-706.

Froidevaux S, Calame-Christe M, Tanner H, et al. 2005. Melanoma targeting with DOTA-alpha-melanocyte-stimulating hormone analogs: structural parameters affecting tumor uptake and kidney uptake. J Nucl Med, 46:887-95.

Fujimoto JG, Pitris C, Boppart SA, et al. 2000. Optical coherence tomography: an emerging technology for biomedical imaging and optical biopsy. Neoplasia, 2:9-25.

Fujimoto JG. 2003. Optical coherence tomography for ultrahigh resolution in vivo imaging. Nat Biotechnol, 21:1361-7.

Funovics MA, Kapeller B, Hoeller C, et al. 2004. MR imaging of the her2/neu and 9.2.27 tumor antigens using immunospecific contrast agents. Magn Reson Imaging, 22:843-50.

Fuster D, Chiang S, Johnson G, et al. 2004. Is ${ }^{18} \mathrm{~F}-\mathrm{FDG}$ PET more accurate than standard diagnostic procedures in the detection of suspected recurrent melanoma? J Nucl Med, 45:1323-7.

Gambhir SS, Czernin J, Schwimmer J, et al. 2001. A tabulated summary of the FDG PET literature. $J$ Nucl Med, 42:1S-93S.

Gambichler T, Moussa G, Sand M, et al. 2005. Applications of optical coherence tomography in dermatology. J Dermatol Sci, 40:85-94.

Gambichler T, Orlikov A, Vasa R, et al. 2007a. In vivo optical coherence tomography of basal cell carcinoma. J Dermatol Sci, 45:167-73.

Gambichler T, Regeniter P, Bechara FG, et al. 2007b. Characterization of benign and malignant melanocytic skin lesions using optical coherence tomography in vivo. $J$ Am Acad Dermatol, 57:629-37.

Garbe C, and Eigentler TK. 2007. Diagnosis and treatment of cutaneous melanoma: state of the art 2006. Melanoma Res, 17:117-27.

Gasparri A, Moro M, Curnis F, et al. 1999. Tumor pretargeting with avidin improves the therapeutic index of biotinylated tumor necrosis factor alpha in mouse models. Cancer Res, 59:2917-23.

Gerger A, Hofmann-Wellenhof R, Langsenlehner U, et al. 2008. In vivo confocal laser scanning microscopy of melanocytic skin tumours: diagnostic applicability using unselected tumour images. Br J Dermatol, 158:329-33.

Gerger A, Koller S, Weger W, et al. 2006. Sensitivity and specificity of confocal laser-scanning microscopy for in vivo diagnosis of malignant skin tumors. Cancer, 107:193-200.

Giblin MF, Jurisson SS, and Quinn TP. 1997. Synthesis and characterization of rhenium-complexed alpha-melanotropin analogs. Bioconjug Chem, $8: 347-53$. 
Giblin MF, Wang N, Hoffman TJ, et al. 1998. Design and characterization of alpha-melanotropin peptide analogs cyclized through rhenium and technetium metal coordination. Proc Natl Acad Sci U S A, 95:12814-8.

Gladkova ND, Shakhova NM, Shakhov BE, et al. 2004. Optic coherent tomography: a new high-resolution technology of visualization of tissue structures. Communication II. Optical images of benign and malignant entities. Vestn Rentgenol Radiol, 44-54.

Gonzalez S, and Gilaberte-Calzada Y. 2008. In vivo reflectance-mode confocal microscopy in clinical dermatology and cosmetology. Int J Cosmet Sci, 30:1-17.

Guy M, Singer D, Barzilai N, et al. 1994. Primary classic Kaposi's sarcoma of glans penis - appearance on magnetic resonance imaging. Br J Urol, 74:521-2.

Hafner J, Schmid MH, Kempf W, et al. 2004. Baseline staging in cutaneous malignant melanoma. Br J Dermatol, 150:677-86.

Hamilton S, Odili J, Gundogdu O, et al. 2001. Improved production by domain inversion of single-chain Fv antibody fragment against high molecular weight proteoglycan for the radioimmunotargeting of melanoma. Hybrid Hybridomics, 20:351-60.

Happe M, Freitag M, Stucker M, et al. 1997. High resolution $20 \mathrm{MHz}$ ultrasound diagnosis in dermatology for noninvasive imaging of malignant melanomas. Z Arztl Fortbild Qualitatssich, 91:347-53.

Harland CC, Bamber JC, Gusterson BA, et al. 1993. High frequency, high resolution B-scan ultrasound in the assessment of skin tumours. Br J Dermatol, 128:525-32.

Haubner R, Bruchertseifer F, Bock M, et al. 2004a. Synthesis and biological evaluation of a ${ }^{99 \mathrm{~m}} \mathrm{Tc}$-labelled cyclic RGD peptide for imaging the $\alpha_{\mathrm{v}} \beta_{3}$ expression. Nuklearmedizin, 43:26-32.

Haubner R, Kuhnast B, Mang C, et al. 2004b. [ $\left.{ }^{18} \mathrm{~F}\right]$ Galacto-RGD: synthesis, radiolabeling, metabolic stability, and radiation dose estimates. Bioconjug Chem, 15:61-9.

Haubner R, Weber WA, Beer AJ, et al. 2005. Noninvasive visualization of the activated $\alpha_{v} \beta_{3}$ integrin in cancer patients by positron emission tomography and $\left[{ }^{18} \mathrm{~F}\right]$ galacto-RGD. PLoS Med, 2:e70.

Haubner R, Wester HJ, Reuning U, et al. 1999. Radiolabeled $\alpha_{\mathrm{v}} \beta_{3}$ integrin antagonists: a new class of tracers for tumor targeting. $J$ Nucl Med, 40:1061-71.

Haubner R, Wester H-J, Weber WA, et al. 2001. Noninvasive imaging of $\alpha_{\mathrm{v}} \beta_{3}$ integrin expression using ${ }^{18} \mathrm{~F}$-labeled RGD-containing glycopeptide and positron emission tomography. Cancer Res, 61:1781-5.

Healy E. 2004. Melanocortin 1 receptor variants, pigmentation, and skin cancer susceptibility. Photodermatol Photoimmunol Photomed, 20:283-8.

Hood JD, and Cheresh DA. 2002. Role of integrins in cell invasion and migration. Nat Rev Cancer, 2:91-100

Horn M, Gerger A, Koller S, et al. 2007. The use of confocal laser-scanning microscopy in microsurgery for invasive squamous cell carcinoma Br J Dermatol, 156:81-4.

Houston JP, Ke S, Wang W, et al. 2005. Quality analysis of in vivo near-infrared fluorescence and conventional gamma images acquired using a dual-labeled tumor-targeting probe. J Biomed Opt, 10:054010.

Jang BS, Lim E, Hee Park S, et al. 2007. Radiolabeled high affinity peptidomimetic antagonist selectively targets $\alpha_{v} \beta_{3}$ receptor-positive tumor in mice. Nucl Med Biol, 34:363-70.

Jovanovic DL, Katic V, and Jovanovic B. 2005. Value of preoperative determination of skin tumor thickness with $20-\mathrm{MHz}$ ultrasound Arch Dermatol, 141:269-70.

Kenny LM, Coombes RC, Oulie I, et al. 2008. Phase I trial of the positron-emitting Arg-Gly-Asp (RGD) peptide radioligand ${ }^{18} \mathrm{~F}-\mathrm{AH} 111585$ in breast cancer patients. J Nucl Med, 49:879-86.

King DM. 2006. Imaging of metastatic melanoma. Cancer Imaging, 6:204-8

Kumar R, and Alavi A. 2005. Clinical applications of fluorodeoxyglucose - positron emission tomography in the management of malignant melanoma. Curr Opin Oncol, 17:154-9.
Kuphal S, Bauer R, and Bosserhoff AK. 2005. Integrin signaling in malignant melanoma. Cancer Metastasis Rev, 24:195-222.

Lamki LM, Zukiwski AA, Shanken LJ, et al. 1990. Radioimaging of melanoma using ${ }^{99 \mathrm{~m}} \mathrm{Tc}$-labeled Fab fragment reactive with a high molecular weight melanoma antigen. Cancer Res, 50:904s-8s.

Langley RG, Walsh N, Sutherland AE, et al. 2007. The diagnostic accuracy of in vivo confocal scanning laser microscopy compared to dermoscopy of benign and malignant melanocytic lesions: a prospective study. Dermatology, 215:365-72.

Larson SM, Carrasquillo JA, McGuffin RW, et al. 1985. Use of I-131 labeled, murine Fab against a high molecular weight antigen of human melanoma: preliminary experience. Radiology, 155:487-92.

Lassau N, Chami L, and Peronneau P. 2007. Imaging of melanoma: accuracy of ultrasonography before and after contrast injection for diagnostic and early evaluation of treatments. Bull Cancer, 94:93-8.

Lassau N, Mercier S, Koscielny S, et al. 1999. Prognostic value of high-frequency sonography and color Doppler sonography for the preoperative assessment of melanomas. AJR Am J Roentgenol, 172:457-61.

Lassau N, Spatz A, Avril MF, et al. 1997. Value of high-frequency US for preoperative assessment of skin tumors. Radiographics, 17:1559-65.

Le Doussal JM, Gruaz-Guyon A, Martin M, et al. 1990. Targeting of indium 111-labeled bivalent hapten to human melanoma mediated by bispecific monoclonal antibody conjugates: imaging of tumors hosted in nude mice. Cancer Res, 50:3445-52.

Le Pape A, Barot-Ciorbaru R, Musset M, et al. 1986. An original method for submacroscopic metastases visualization in cases of cancer minimal residual disease. Biomed Pharmacother, 40:392-8.

Lee FT, Rigopoulos A, Hall C, et al. 2001. Specific localization, gamma camera imaging, and intracellular trafficking of radiolabelled chimeric anti-G(D3) ganglioside monoclonal antibody KM871 in SK-MEL-28 melanoma xenografts. Cancer Res, 61:4474-82.

Lieber CA, Majumder SK, Billheimer D, et al. 2008. Raman microspectroscopy for skin cancer detection in vitro. J Biomed Opt, 13:024013.

Loffler T, Siebert K, Czasch S, et al. 2002. Visualization and classification in biomedical terahertz pulsed imaging. Phys Med Biol, 47:3847-52.

Lotze MT, Carrasquillo JA, Weinstein JN, et al. 1986. Monoclonal antibody imaging of human melanoma. Radioimmunodetection by subcutaneous or systemic injection. Ann Surg, 204:223-35.

Macapinlac HA. 2004. FDG PET and PET/CT imaging in lymphoma and melanoma. Cancer J, 10:262-70.

Macfarlane DJ, Sondak V, Johnson T, et al. 1998. Prospective evaluation of $2-\left[{ }^{18} \mathrm{~F}\right]$-2-deoxy-D-glucose positron emission tomography in staging of regional lymph nodes in patients with cutaneous malignant melanoma. J Clin Oncol, 16:1770-6.

Mankoff DA. 2007. A definition of molecular imaging. J Nucl Med, $48: 18 \mathrm{~N}, 21 \mathrm{~N}$.

Massoud TF, and Gambhir SS. 2003. Molecular imaging in living subjects: seeing fundamental biological processes in a new light. Genes Dev, 17:545-80.

McQuade P, Miao Y, Yoo J, et al. 2005. Imaging of melanoma using ${ }^{64} \mathrm{Cu}$ - and ${ }^{86} \mathrm{Y}$-DOTA-ReCCMSH(Arg11), a cyclized peptide analogue of alpha-MSH. J Med Chem, 48:2985-92.

Miao Y, and Quinn TP. 2007. Alpha-melanocyte stimulating hormone peptide-targeted melanoma imaging. Front Biosci, 12:4514-24.

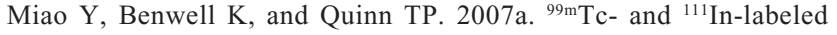
alpha-melanocyte-stimulating hormone peptides as imaging probes for primary and pulmonary metastatic melanoma detection. $J \mathrm{Nucl}$ Med, 48:73-80.

Miao Y, Figueroa SD, Fisher DR, et al. 2008a. ${ }^{203} \mathrm{~Pb}$-labeled $\alpha$-melanocyte-stimulating hormone peptide as an imaging probe for melanoma detection. J Nucl Med, 49:823-9.

Miao Y, Fisher DR, and Quinn TP. 2006. Reducing renal uptake of ${ }^{90} \mathrm{Y}$ - and ${ }^{177} \mathrm{Lu}$-labeled alpha-melanocyte stimulating hormone peptide analogues. Nucl Med Biol, 33:723-33.

Miao Y, Gallazzi F, Guo H, et al. 2008b. ${ }^{111}$ In-labeled lactam bridge-cyclized alpha-melanocyte stimulating hormone peptide analogues for melanoma imaging. Bioconjug Chem, 19:539-47. 
Miao Y, Hoffman TJ, and Quinn TP. 2005a. Tumor-targeting properties of ${ }^{90} \mathrm{Y}$ - and ${ }^{177} \mathrm{Lu}$-labeled alpha-melanocyte stimulating hormone peptide analogues in a murine melanoma model. Nucl Med Biol, 32:485-93.

Miao Y, Hylarides M, Fisher DR, et al. 2005b. Melanoma therapy via peptide-targeted $\alpha$-radiation. Clin Cancer Res, 11:5616-21.

Miao Y, Owen NK, Fisher DR, et al. 2005c. Therapeutic efficacy of a ${ }^{188}$ Relabeled alpha-melanocyte-stimulating hormone peptide analog in murine and human melanoma-bearing mouse models. J Nucl Med, 46:121-9.

Miao Y, Shelton T, and Quinn TP. 2007b. Therapeutic efficacy of a ${ }^{177} \mathrm{Lu}$-labeled DOTA conjugated alpha-melanocyte-stimulating hormone peptide in a murine melanoma-bearing mouse model. Cancer Biother Radiopharm, 22:333-41.

Miao Y, Whitener D, Feng W, et al. 2003. Evaluation of the human melanoma targeting properties of radiolabeled alpha-melanocyte stimulating hormone peptide analogues. Bioconjug Chem, 14:1177-84.

Milner SM, Memar OM, Gherardini G, et al. 1997. The histological interpretation of high frequency cutaneous ultrasound imaging. Dermatol Surg, 23:43-5.

Minsky M. 1988. Memoir on inventing the confocal scanning microscope. Scanning, 10:128-38.

Mogensen M, and Jemec GB. 2007. Diagnosis of nonmelanoma skin cancer/keratinocyte carcinoma: a review of diagnostic accuracy of nonmelanoma skin cancer diagnostic tests and technologies. Dermatol Surg, 33:1158-74

Moore JV, and Allan E. 2003. Pulsed ultrasound measurements of depth and regression of basal cell carcinomas after photodynamic therapy: relationship to probability of 1-year local control. $\mathrm{Br} J$ Dermatol, 149:1035-40.

Moulin-Romsee G, Benamor M, and Neuenschwander S. 2008. Desmoplastic neurotropic melanoma in a patient with trigeminal neuralgia: FDG PET/CT and MRI. Clin Nucl Med, 33:353-5.

Mountjoy KG, Robbins LS, Mortrud MT, et al. 1992. The cloning of a family of genes that encode the melanocortin receptors. Science, 257:1248-51.

Mueller CS, and Reichrath J. 2008. Histology of melanoma and nonmelanoma skin cancer. Adv Exp Med Biol, 624:215-26.

Murray JL, Rosenblum MG, Lamki L, et al. 1987. Radioimmunoimaging in malignant melanoma patients with the use of indium-111-labeled antimelanoma monoclonal antibody (ZME-018) to high-molecular-weight antigen. NCI Monogr, 3-9.

Naito S, Min YK, Sugata K, et al. 2008. In vivo measurement of human dermis by $1064 \mathrm{~nm}$-excited fiber Raman spectroscopy. Skin Res Technol, 14:18-25.

Nehal KS, Gareau D, and Rajadhyaksha M. 2008. Skin imaging with reflectance confocal microscopy. Semin Cutan Med Surg, 27:37-43.

Newton JR, Miao Y, Deutscher SL, et al. 2007. Melanoma imaging with pretargeted bivalent bacteriophage. J Nucl Med, 48:429-36.

Olmedo JM, Warschaw KE, Schmitt JM, et al. 2006. Optical coherence tomography for the characterization of basal cell carcinoma in vivo: a pilot study. J Am Acad Dermatol, 55:408-12.

Olmedo JM, Warschaw KE, Schmitt JM, et al. 2007. Correlation of thickness of basal cell carcinoma by optical coherence tomography in vivo and routine histologic findings: a pilot study. Dermatol Surg, 33:421-5; discussion 5-6.

Ono I, Sakemoto A, Ogino J, et al. 2006. The real-time, three-dimensional analyses of benign and malignant skin tumors by confocal laser scanning microscopy. J Dermatol Sci, 43:135-41.

Palmowski M, Huppert J, Ladewig G, et al. 2008. Molecular profiling of angiogenesis with targeted ultrasound imaging: early assessment of antiangiogenic therapy effects. Mol Cancer Ther, 7:101-9.

Paolino D, Cosco D, Muzzalupo R, et al. 2008. Innovative bola-surfactant niosomes as topical delivery systems of 5-fluorouracil for the treatment of skin cancer. Int J Pharm, 353:233-42.

Patel YG, Nehal KS, Aranda I, et al. 2007. Confocal reflectance mosaicing of basal cell carcinomas in Mohs surgical skin excisions. J Biomed Opt, 12:034027.
Pellacani G, Cesinaro AM, and Seidenari S. 2005a. In vivo assessment of melanocytic nests in nevi and melanomas by reflectance confocal microscopy. Mod Pathol, 18:469-74.

Pellacani G, Cesinaro AM, and Seidenari S. 2005b. Reflectance-mode confocal microscopy of pigmented skin lesions - improvement in melanoma diagnostic specificity. J Am Acad Dermatol, 53:979-85.

Peters K, and Vejlsgaard GL. 1992. Basal cell and squamous cell carcinoma and Kaposi's sarcoma. Curr Opin Oncol, 4:380-5.

Pierce MC, Strasswimmer J, Park BH, et al. 2004. Advances in optical coherence tomography imaging for dermatology. J Invest Dermatol, 123:458-63.

Rajeswari MR, Jain A, Sharma A, et al. 2003. Evaluation of skin tumors by magnetic resonance imaging. Lab Invest, 83:1279-83.

Rass K, and Tilgen W. 2008. Treatment of melanoma and nonmelanoma skin cancer. Adv Exp Med Biol, 624:296-318.

Roman Kuranov VS, I. Turchin, E. Zagainova, V. Gelikonov, V. Kamensky, L. Snopova, and N. Prodanetz 2002. Complementary use of cross-polarization and standard OCT for differential diagnosis of pathological tissues. Optics Express, 10:707-13.

Rosenblum MG, Marks JW, and Cheung LH. 1999. Comparative cytotoxicity and pharmacokinetics of antimelanoma immunotoxins containing either natural or recombinant gelonin. Cancer Chemother Pharmacol, 44:343-8.

Rossi R, Mori M, and Lotti T. 2007. Actinic keratosis. Int J Dermatol, 46:895-904.

Ruoslahti E. 1996. RGD and other recognition sequences for integrins. Annu Rev Cell Dev Biol, 12:697-715.

Rupprecht M, Mensing CH, Barvencik F, et al. 2007. Skeletal and dermatological manifestations of the nevoid Basal cell carcinoma syndrome (GorlinGoltz syndrome). Results of 8 patients in 12 years. Rofo, 179:618-26.

Rusciano D. 2000. Differentiation and metastasis in melanoma. Crit Rev Oncog, 11:147-63.

Salvini C, Massi D, Cappetti A, et al. 2008. Application of optical coherence tomography in non-invasive characterization of skin vascular lesions. Skin Res Technol, 14:89-92.

Schafer-Hesterberg G, Schoengen A, Sterry W, et al. 2007. Use of ultrasound to early identify, diagnose and localize metastases in melanoma patients. Expert Rev Anticancer Ther, 7:1707-16.

Schmid-Wendtner MH, and Burgdorf W. 2005. Ultrasound scanning in dermatology. Arch Dermatol, 141:217-24.

Schmieder AH, Winter PM, Caruthers SD, et al. 2005. Molecular MR imaging of melanoma angiogenesis with $\alpha_{4} \beta_{3}$-targeted paramagnetic nanoparticles. Magn Reson Med, 53:621-7.

Schwartz RA, Bridges TM, Butani AK, et al. 2008. Actinic keratosis: an occupational and environmental disorder. $J$ Eur Acad Dermatol Venereol, 22:606-15.

Scope A, Gill M, Benveuto-Andrade C, et al. 2007. Correlation of dermoscopy with in vivo reflectance confocal microscopy of streaks in melanocytic lesions. Arch Dermatol, 143:727-34.

Seftor RE. 1998. Role of the $\beta_{3}$ integrin subunit in human primary melanoma progression: multifunctional activities associated with $\alpha_{v} \beta_{3}$ integrin expression. Am. J. Pathol, 153:1347-51.

Segura S, Puig S, Carrera C, et al. 2007. Dendritic cells in pigmented basal cell carcinoma: a relevant finding by reflectance-mode confocal microscopy. Arch Dermatol, 143:883-6.

Sergieva SB, and Virtcheva-Genkova A. 1997. Radioimmunoscintigraphy in patients with ocular melanoma. Clin $\mathrm{Nucl} \mathrm{Med,} \mathrm{22:25-9.}$

Sharkey RM, Cardillo TM, Rossi EA, et al. 2005. Signal amplification in molecular imaging by pretargeting a multivalent, bispecific antibody. Nat Med, 11:1250-5.

Sivolapenko GB, Skarlos D, Pectasides D, et al. 1998. Imaging of metastatic melanoma utilising a technetium-99m labelled RGD-containing synthetic peptide. Eur J Nucl Med, 25:1383-9.

Streit M, and Detmar M. 2003. Angiogenesis, lymphangiogenesis, and melanoma metastasis. Oncogene, 22:3172-9.

Sturm RA, Duffy DL, Box NF, et al. 2003. The role of melanocortin-1 receptor polymorphism in skin cancer risk phenotypes. Pigment Cell Res, 16:266-72. 
Svec J, Veselovska Z, Keszeghova V, et al. 1989. Radioimmunoscintigraphy of human malignant melanoma. I. Pharmacokinetics and localization of ${ }^{125}$ I-labeled monoclonal antibody RG-12 in thymectomized mice bearing renal melanoma xenotransplants. Neoplasma, 36:505-11.

Swetter SM, Carroll LA, Johnson DL, et al. 2002. Positron emission tomography is superior to computed tomography for metastatic detection in melanoma patients. Ann Surg Oncol, 9:646-53.

Tai P. 2008. Merkel cell cancer: update on biology and treatment. Curr Opin Oncol, 20:196-200.

Tatro JB, Wen Z, Entwistle ML, et al. 1992. Interaction of an alphamelanocyte-stimulating hormone-diphtheria toxin fusion protein with melanotropin receptors in human melanoma metastases. Cancer Res, 52:2545-8.

Taylor A, Jr., Milton W, Eyre HP, et al. 1988. Radioimmunodetection of human melanoma with indium-111-labeled monoclonal antibody. J Nucl Med, 29:329-37.

Tillman DK, Jr, and Carroll MT. 2007. Topical imiquimod therapy for basal and squamous cell carcinomas: a clinical experience. Cutis, 79:241-8.

Ueno Y, and Ajito K. 2008. Analytical terahertz spectroscopy. Anal Sci, 24:185-92.

Ulrich M, Maltusch A, Rius-Diaz F, et al. 2008. Clinical applicability of in vivo reflectance confocal microscopy for the diagnosis of actinic keratoses. Dermatol Surg, 34:610-9.

Ulrich M, Stockfleth E, Roewert-Huber J, et al. 2007. Noninvasive diagnostic tools for nonmelanoma skin cancer. $\mathrm{Br} J$ Dermatol, 157 (Suppl 2):56-8.

Uren RF, Sanki A, and Thompson JF. 2007. The utility of ultrasound in patients with melanoma. Expert Rev Anticancer Ther, 7:1633-42.

Vaidyanathan G, and Zalutsky MR. 1997. Fluorine-18-labeled [Nle ${ }^{4}, \mathrm{D}-\mathrm{Phe}^{7}$ ]alpha-MSH, an alpha-melanocyte stimulating hormone analogue. $\mathrm{Nucl}$ Med Biol, 24:171-8.

Vanea E, Charlier N, Dewever J, et al. 2008. Molecular electron paramagnetic resonance imaging of melanin in melanomas: a proof-of-concept. $N M R$ Biomed, 21:296-300.

Vera DR, Wallace AM, and Hoh CK. 2001. [ $\left.{ }^{99 \mathrm{~m}} \mathrm{Tc}\right] \mathrm{MAG}_{3}$-mannosyl-dextran: a receptor-binding radiopharmaceutical for sentinel node detection. $\mathrm{Nucl}$ Med Biol, 28:493-8.

Voss SD, Smith SV, DiBartolo N, et al. 2007. Positron emission tomography (PET) imaging of neuroblastoma and melanoma with ${ }^{64} \mathrm{Cu}-\mathrm{SarAr}$ immunoconjugates. Proc Natl Acad Sci U S A, 104:17489-93.
Vossen JA, Buijs M, and Kamel IR. 2006. Assessment of tumor response on MR imaging after locoregional therapy. Tech Vasc Interv Radiol, 9:125-32.

Wahl RL, Kaminski MS, Ethier SP, et al. 1990a. The potential of 2-deoxy-2[ $\left.{ }^{18} \mathrm{~F}\right]$ fluoro-D-glucose (FDG) for the detection of tumor involvement in lymph nodes. $J$ Nucl Med, 31:1831-5.

Wahl RL, Liebert M, Headington J, et al. 1990b. Lymphoscintigraphy in melanoma: initial evaluation of a low protein dose monoclonal antibody cocktail. Cancer Res, 50:941s-8s.

Wahl RL, Wilson BS, Liebert M, et al. 1987. High-dose, unlabeled, nonspecific antibody pretreatment: influence on specific antibody localization to human melanoma xenografts. Cancer Immunol Immunother, 24:221-4.

Walker GC, Berry E, Smye SW, et al. 2004. Materials for phantoms for terahertz pulsed imaging. Phys Med Biol, 49:N363-9.

Wallace AM, Hoh CK, Ellner SJ, et al. 2007. Lymphoseek: a molecular imaging agent for melanoma sentinel lymph node mapping. Ann Surg Oncol, 14:913-21.

Wallace VP, Fitzgerald AJ, Shankar S, et al. 2004. Terahertz pulsed imaging of basal cell carcinoma ex vivo and in vivo. Br J Dermatol, 151:424-32.

Wang L, Xie X, Oh JT, et al. 2005. Combined photoacoustic and molecular fluorescence imaging in vivo. Conf Proc IEEE Eng Med Biol Soc, $1: 190-2$.

Wang W, Ke S, Wu Q, et al. 2004. Near-infrared optical imaging of integrin $\alpha_{4} \beta_{3}$ in human tumor xenografts. Mol Imaging, 3:343-51.

Wei L, Butcher C, Miao Y, et al. 2007a. Synthesis and biologic evaluation of ${ }^{64} \mathrm{Cu}$-labeled rhenium-cyclized alpha-MSH peptide analog using a cross-bridged cyclam chelator. $J$ Nucl Med, 48:64-72.

Wei L, Miao Y, Gallazzi F, et al. 2007b. Gallium-68-labeled DOTA-rhenium-cyclized alpha-melanocyte-stimulating hormone analog for imaging of malignant melanoma. Nucl Med Biol, 34:945-53.

Wollina U, Nelskamp C, Scheibe A, et al. 2007. Fluorescence-remission sensoring of skin tumours: preliminary results. Skin Res Technol, 13:463-71.

Woodward RM, Wallace VP, Pye RJ, et al. 2003. Terahertz pulse imaging of ex vivo basal cell carcinoma. J Invest Dermatol, 120:72-8.

Xiong JP, Stehle T, Diefenbach B, et al. 2001. Crystal structure of the extracellular segment of integrin $\alpha_{\mathrm{v}} \beta_{3}$. Science, 294:339-45.

Zhang HF, Maslov K, Stoica G, et al. 2006. Functional photoacoustic microscopy for high-resolution and noninvasive in vivo imaging. Nat Biotechnol, 24:848-51. 
